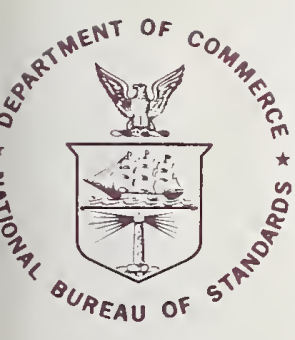

NBS TECHNICAL NOTE 895

U.S. DEPARTMENT OF COMMERCE / National Bureau of Standards

\title{
An Overview of \\ Floor Slip-Resistance Research With Annotated Bibliography
}

QC 100

.45753 no. 895

1976

c. 2 


\section{NATIONAL BUREAU OF STANDARDS}

The National Bureau of Standards ${ }^{1}$ was established by an act of Congress March 3, 1901. The Bureau's overall goal is to strengthen and advance the Nation's science and technology and facilitate their effective application for public benefit. To this end, the Bureau conducts research and provides: (1) a basis for the Nation's physical measurement system, (2) scientific and technological services for industry and government, (3) a technical basis for equity in trade, and (4) technical services to promote public safety. The Bureau consists of the Institute for Basic Standards, the Institute for Materials Research, the Institute for Applied Technology, the Institute for Computer Sciences and Technology, and the Office for Information Programs.

THE INSTITUTE FOR BASIC STANDARDS provides the central basis within the United States of a complete and consistent system of physical measurement; coordinates that system with measurement systems of other nations; and furnishes essential services leading to accurate and uniform physical measurements throughout the Nation's scientific community, industry, and commerce. The Institute consists of the Office of Measurement Services, the Office of Radiation Measurement and the following Center and divisions:

Applied Mathematics - Electricity - Mechanics - Heat - Optical Physics - Center for Radiation Research: Nuclear Sciences; Applied Radiation - Laboratory Astrophysics ${ }^{2}$ - Cryogenics ${ }^{2}$ - Electromagnetics ${ }^{2}$ - Time and Frequency ${ }^{2}$.

THE INSTITUTE FOR MATERIALS RESEARCH conducts materials research leading to improved methods of measurement, standards, and data on the properties of well-characterized materials needed by industry, commerce, educational institutions, and Government; provides advisory and research services to other Government agencies; and develops, produces, and distributes standard reference materials. The Institute consists of the Office of Standard Reference Materials, the Office of Air and Water Measurement, and the following divisions:

Analytical Chemistry — Polymers - Metallurgy - Inorganic Materials — Reactor Radiation - Physical Chemistry.

THE INSTITUTE FOR APPLIED TECHNOLOGY provides technical services to promote the use of available technology and to facilitate technological innovation in industry and Government; cooperates with public and private organizations leading to the development of technological standards (including mandatory safety standards), codes and methods of test; and provides technical advice and services to Government agencies upon request. The Institute consists of the following divisions and Centers:

Standards Application and Analysis — Electronic Technology _ Center for Consumer Product Technology: Product Systems Analysis; Product Engineering - Center for Building Technology: Structures, Materials, and Life Safety; Building Environment; Technićal Evaluation and Application — Center for Fire Research: Fire Science; Fire Safety Engineering.

THE INSTITUTE FOR COMPUTER SCIENCES AND TECHNOLOGY conducts research and provides technical services designed to aid Government agencies in improving cost effectiveness in the conduct of their programs through the selection, acquisition, and effective utilization of automatic data processing equipment; and serves as the principal focus within the executive branch for the development of Federal standards for automatic data processing equipment, techniques, and computer languages. The Institute consists of the following divisions:

Computer Services — Systems and Software - Computer Systems Engineering — Information Technology.

THE OFFICE FOR INFORMATION PROGRAMS promotes optimum dissemination and accessibility of scientific information generated within NBS and other agencies of the Federal Government; promotes the development of the National Standard Reference Data System and a system of information analysis centers dealing with the broader aspects of the National Measurement System; provides appropriate services to ensure that the NBS staff has optimum accessibility to the scientific information of the world. The Office consists of the following organizational units:

Office of Standard Reference Data - Office of Information Activities - Office of Technical Publications - Library - Office of International Relations - Office of International Standards.

\footnotetext{
${ }^{1}$ Headquarters and Laboratories at Gaithersburg, Maryland, unless otherwise noted; mailing address Washington, D.C. 20234.

${ }^{2}$ Located at Boulder, Colorado 80302.
} 


\section{An Overview of Floor Slip-Resistance Research With Annotated Bibliography}

\section{technical notie no. 0.5.}

\section{Robert J. Brungraber}

Structures, Materials and Safety Division

Center for Building Technology

Institute for Applied Technology

National Bureau of Standards

Washington, D.C. 20234

This paper was prepared by the author while he was an

Intergovernmental Personnel Act Appointee in the

Building Safety Section, on leave from Bucknell University,

Lewisburg, Pa.

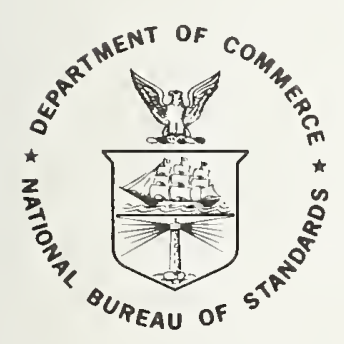

U.S. DEPARTMENT OF COMMERCE, Rogers C. B. Morton, Secretary James A. Baker, III, Under Secretary

Dr. Betsy Ancker-Johnson, Assistant Secretary for Science and Technology

US, NATIONAL BUREAU OF STANDARDS, Ernest Ambler, Acfing Director

Issued January 1976 


\section{National Bureau of Standards Technical Note 895}

Nat. Bur. Stand. (U.S.), Tech. Note 895, 113 pages (Jan. 1976)

CODEN: NBTNAE 
Introduction .................... 1

Gravity of the Problem.............. 2

Kinesiology and Anthropometry. . . . . . . . . . . 3

The General Study of Friction. . . . . . . . . . 4

Critical Appraisal of Past and Current Methods for

Determining Floor Slip-Resistance ......... 5

Guide for Selection of Slip-Resistance Criteria. . . . . . 7

Legal Aspects of the Floor Slip-Resistance Problem and

the Present Status of Floor Slip-Resistance Specifications . 8

\section{APPENDIX}

An Annotated Bibliography on The Slip-Resistance of Floors. . 10

Section A - Analytical Determination of the Required Minimum Value of Coefficient of Friction Needed for Safe Walking, Considering Anthropometry and Kinesiology.. 11

Section B - Experimental Studies of Kinesiology or Human Locomotion, With Specific Measurement of Normal and

Tangential Forces So that Limiting Values of

Coefficient of Friction Can Be Established . . . . 15

Section C - General Treatments of Kinesiology or Human

Locomotion . . . . . . . . . . . . . 21

Section D - Methods and Results of Tests for Floor SlipResistance........... . . 34

Section E - General Discussions of Floor Slip Resistance . . . 70

Section F - Legal Aspects of the Floor Slip-Resistance Problem and the Present Status of Floor Slip-Resistance Specifications ........... . . 78

Section G - Basic Principles of Friction . . . . . . . . 93

Section $H$ - An Alphabetical Listing of all ltems in the Bibliography .............. . 99 

An Overview of Floor Slip-Resistance Research

With Annotated Bibliography

Robert J. Brungraber

Slips and falls in the home as well as in public buildings have reached serious proportions $(8,000,000$ accidents per year in the home, resulting in 9,600 deaths and 1,600,000 disabling injuries). This paper reviews the literature relating to this problem. Based on studies of kinesiology and anthropometry, the coefficient of friction between foot surfaces and floor surfaces is found to be a significant parameter controlling slips and falls. A review of the general study of friction and a critical appraisal of methods for determining the coefficient of friction on slip-resistance of floors leads to a guide for selection of slip-resistance criteria. The paper concludes with a discussion of the legal aspects of the problem and the present status of slip-resistance specifications.

Key words: Building safety; floor surface friction; occupancy safety; slip-resistance; slip-resistance testers; walking friction.

\section{Introduction}

The seriousness of the problem of slips and falls $(8,000,000$ accidents per year in the home, resulting in 9,600 deaths and 1,600,000 disabling injuries) has prompted the Building Safety Section of the National Bureau of Standards to initiate a program to investigate the contribution of floor slip-resistance to this problem. The ultimate aim of this study is the development of a method for the evaluation of floor slipresistance and the establishment of criteria for the safe control of it.

This second of a planned series of reports describing the results of the study is based on an extensive search of the literature relating to slip-resistance in general and floor slip-resistance in particular. The report consists of a general discussion of the slipperiness problem and the results of past efforts to address it, followed by an annotated bibliography.

The bibliography is organized in sections for ready reference by the reader to specific areas of the slip-resistance problem. Significant portions of many of the references are abstracted so that a reader interested in subject and scope only will not have to go to the source. Also material directly applicable to the establishment of slip-resistance standards has been abstracted. Section $H$ of the appendix is an alphabetical 1 ist of all the bibliography items. 
Since this report is a product of the Bailding Safety Section it concentrates on background material that could be useful to the building owner in his efforts to control slip-resistance, for example, by his selection of flooring materials and treatment products and processes. Thus such topics as shoe materials and construction and psychological factors of the walker are treated only insofar as they relate to the development of test methods for evaluating flooring materials and treatment products and processes.

\section{Gravity of the Problem}

Injuries resulting from slips and falls, particularly as they are related to the relative slip-resistance of shoes and flooring surfaces, result in serious human discomfort and loss of life as well as significant financial losses.

For example, the 1974 edition of "Accident Facts," published by the National Safety Council, indicates that annually $8,000,000$ falls occur in the home, resulting in 1,600,000 disabling injuries and 9,600 deaths; most of the deaths occurring among the aged, older than 65. Further, Rodstein in $1963(E-9)$ * reported that the combined general liability experience of three large department store.chains for a three year period showed a total of 8,637 accidents with losses of $\$ 665,000$. Fully a third of these accidents were falls on stairways and floors with $17 \%$ of them, resulting in $20 \%$ of the 1oss, being falls on floors. Schuster, in a German paper of 1966 (A-3), reports accident statistics for one year of $2,508 \mathrm{fa} 11 \mathrm{~s}, 93 \%$ of them on level surfaces; the rest on stairs. For falls on level surfaces slip or slipperiness was usually considered the most important factor. In '1964 Esmay and Segerlind (D-10) quoted the National Safety Council in reporting that in 1959 alone more than $2200 \mathrm{farm}$ people died as a result of falls. About one third of these accidents occurred on steps and stairways.

The seriousness of this problem has resulted in continuing research by the manufacturers of floor waxes and polishes (A-2, D-3, D-15, D-38, D39) many shoe manufacturers (D-4, D-26) and userśs (D-40); insurance laboratories such as that maintained by the Liberty Mutual Organization (D-13, D-22, D-23); numerous government laboratories (state, federal and foreign) such as the National Bureau of Standards' efforts dating back to the 1920's $(B-5, D-2, D-20, D-34, D-36)$. It is the purpose of this paper to assemble this material to serve as a starting point for yet another attempt to bring increased understanding to this complex problem.

*Alphanumeric designations in parentheses refer to items in the attached bibliography. 
A complete understanding of all causes of slips and falls would necessitate a thorough knowledge of kinesiology, the study of the principles of mechanics and anatomy in relation to human movement. However, from the standpoint of the building owner or his designated agent only the material and the geometrical layout of the walking surfaces of the building is under their control. It is clear that a walking surface can be too slippery to permit safe walking. It may also be that a walking surface could be too slip-resistant to permit safe, convenient walking. Thus clearly the slip-resistance of the shoe-floor surface interface is a significant factor in the slip-fall equation. For this reason some means for evaluating and controlling the slip-resistance of floors is essential. However, this means of evaluating slip-resistance must be based on a study of kinesiology to the extent that the value of slipresistance is such and is measured in such a way as to relate to actual walking. Essentially the following questions must be answered: (1) which coefficient of friction, static or dynamic is of importance to the slip and fall problem and; (2) under what circumstances should it be measured.

The numerous studies of kinesiology (sections $B$ and $C$ of the bibliography) dating back to 1872, have revealed that in "normal walking" there is no relative movement of the foot with respect to the floor, during the period when the foot is in contact with the floor. This is particularly well demonstrated by the report of the Berkeley group (B-3, B-7) where their lapsed time photography and other methods reveal no slipping of the shoe during normal, straight-line, walking. Thus as was claimed by James ( $D-24)$ the most significant parameter controlling the slipresistance of floors is the static coefficient of friction.

Some of the experimental studies of kinesiology made use of a force plate to record the time variations of the forces developed between the floor and the feet of walking subjects. In the cases (section $B$ of the append $i x$ ) where the normal component, $V$, and the tangential or horizontal component, $\mathrm{H}$, were recorded separately, thus permitting the calculation of the ratio, H/V, the results can be used to establish a lower limit for the coefficient of friction needed to permit safe walking.

Considerations of anthropometry, the study of human body measurements, as it describes the geometry of the human stride (section $A$ of the bibliography) permits yet another determination of a lower limit for the coefficient of friction needed for safe walking. The geometry of the human stride can be translated into resulting force components in the legs from which critical values of $H / V$ can again be calculated. 
Although, starting with Leonardo da Vinci, some very famous scientists have studied friction over the centuries (Section $G$ of the bibliography) it still remains one of the most familiar and yet least understood facets of mechanics. This stems largely from the circumstance that its common occurrence has prompted the need for simple rules describing it while it is in fact not a simple phenomenon at a11. Drawing on the deceptively simple yet clear treatment by Rabinowicz $(G-10)$ we find the three basic rules of friction: that the friction force (1) is proportional to the normal force and thus (2) is not affected by the contact area or (3) by the rate of movement. Rules (1) and (2) are borne out by tests within $+10 \%$ in most cases, except for two readily deformable surfaces rubbing together. But rule (3) is frequently violated, particularly at extremely high and extremely low rates of motion. Fortunately for considerations of the slipperiness of floors, high velocities are of no interest and extremely low velocities are of only academic interest. Just as the ancient Greek philosopher, Heraclitus, claimed that everything flows, as indeed it does if you adopt a long enough time frame; and just as the proportional limit of a supposedly elastic material tends toward zero as the precision of the strain gage is increased; so does the static coefficient of friction tend towards zero as the rate of loading is decreased. However, within the time frame of a normal step the static coefficient of friction will not be zero, but actually greater than the dynamic coefficient of friction. Rabinowicz (G-10) summarizes this in the four curves, reproduced as Fig. 1, which depict the history of the development of our knowledge of friction vs. velocity.

A friction problem more directly related to floors is the increase in the static coefficient of friction with the increase in time delay between the application of the normal loads and the tangential or sliding load as noted by Braun and Roemer (D-3) and Gavan and Vanaman (D-15). According to Gomer \& Smith $(G-7)$, Moore $(G-9)$ and Rabinowicz $(G-10)$ this is caused by adhesion which in many cases is enhanced by the presence of water between the sliding surfaces. This may very well be the explanation for the increase in coefficient of friction of leather soles by wetting that has been observed by many investigators (D-6, D-20, D-23, D-33, D34). This points up the need for a friction measuring device that closely approximates the time delay that is representative of a normal step and that is generally repeatable. Most of the presently available friction testers introduce a time delay that is of indeterminate length but generally much longer than the time needed to execute a normal step. 
Critical Appraisal of Past and Current Methods for Determining Floor Slip-Resistance

Most of the methods currently used for the determination of floor slipresistance have been thoroughly described in Section D of the Bibliography and summarized in E-1 and E-3. They can best be considered in three categories:

(1) A drag type meter. This consists of a weight of known value, having a facing of a certain shoe sole or heel material, which can be drawn across a floor surface in such a way as to permit the measurement of the forces needed to incipiate motion (static friction) and maintain motion (dynamic friction);

(2) A pendulum type meter. This consists of a pendulum, faced with a certain shoe sole or heel material, which can be adjusted to sweep a path across a flooring surface so that the contact pressure between the facing and the floor follows a predetermined time-dependency. The resulting loss of energy of the pendulum is claimed to be a measure of the dynamic friction;

(3) An articulated strut. This applies a known vertical force to a shoe faced with a certain sole or heel material and then applies an increasing lateral force until slip occurs. The ratio of lateral force at slip to the known vertical force is the static coefficient of friction.

Examples of the drag type meter are the Horizontal Pull Slipmeter (D$22)$, the TOPAKA (D-39), and more sophisticated devices such as that described by Braun and Roemer (D-3).

Some researchers claim that the drag type meter can measure both static and dynamic friction. However Irvine, the developer of the Horizontal Pull slipmeter, has found that the dynamic and static coefficients are both seriously influenced by the velocity at which the meter is pulled and thus has found it necessary to supply a capstan head motor to pull the meter at a constant velocity. Even then, as has been demonstrated by Braun \& Roemer, dynamic effects seriously influence both the static and the dynamic readings. The static reading is affected by the force required to accelerate the weight which supplies the normal load and, since this is the weight of the entire device, the error can be significant. In measuring the dynamic friction the phenomenon of stick-slip frequently develops and this has been found to be a function of the elasticity of the device, particularly portions of the prime mover such as the string of the capstan-headed motor of the Horizontal Pull Slipmeter and the TOPAKA.

The pendulum type, as represented by the Sigler (D-34, D-35) and The British Portable Skid Tester (BPST), (D-16, D-21, D-36) measures only the dynamic friction and this as some sort of integrated function resulting in a measured energy loss of the pendulum. This makes the adjustment 
of this device quite critical and, as has been shown above, the dynamic coefficient of friction is not of prime importance in controlling slipresistance. Slow motion films of some BPST tests conducted at the National Bureau of Standards as well as some tests made on bond paper over a sheet of carbon paper (D-25) show that the contact pressure varies erratically with time so that it would be difficult, if not impossible, to relate friction directly to the energy loss. The British Portable Skid Tester is intended to simulate a $30 \mathrm{mph}$ skid which is hardly representative of maneuvers of the feet that occur during normal walking.

Finally the articulated strut device, as represented by the James (D-24) and Hunter (D-20) machines, is based on the direct and fundamental principle of the resolution of forces. The Hunter device has the disadvantage that it measures the dynamic friction since the shoe is pulled across the floor until uncontrolled slip occurs, at which time the tangent of the resulting angle of the strut is measured. Thus the shoe is actually in motion when the measurement is taken. The James machine does measure static friction but for some reason, not explained in James' article (D-24), the final version of his device is strictly a laboratory machine suitable only for evaluating flooring materials, not floors. From the description of his device in his 1944 paper, tests could be made directly on floors with the initial design but as is the case for the Hunter, the surcharge is 75-80 1bs. and this makes the device portable only with difficulty (a portable version of the Hunter machine was developed by Gurney [D-18]). Many investigators have shown that, within rather broad limits, the coefficient of friction between typical shoe and flooring materials is not sensitive to variations in contact pressure (D-20, D-24, D-38). Thus it would seem that one of the major reasons for employing such large surcharges on the Hunter and James machines is to reduce the errors arising from the internal friction in these devices. 
Guide for Selection of Slip-Resistance Criteria

Considering that the slip-resistance can be controlled by specifying values of the static coefficient of friction, how should these specified values be selected? There are three sources of information that can be used to select these values; (1) experimental kinesiology or measurement of the forces exerted by the shod foot upon the floor, (2) anthropometry or the geometry of the walking body, and (3) friction measurements made on walkway surfaces having known safety records. In setting recommended values for floor slip-resistance or static coefficient of friction it may very well be that for certain walking maneuvers the friction could be too high and thus the recommendation should be in the form of both upper and lower limits.

Of the many references on experimental kinesiology (sections B \& $C$ of the bibliography) only a few (section B) report both the normal force, $V$, and the tangential force, $H$, so that required values of $H / V$ or $\mu$ can be established. These relate to normal walking in a straight line, walking around a curve and walking up and down ramps, for both normal people and people with artificial limbs.

There have been several studies of anthropometry, or the geometry of the walking body, some of these also include consideration of the forces needed to accelerate the body (section A). These studies indicate that for the longest stride likely to be taken in walking the required minimum static coefficient of friction would be 0.5 . For running, the same study (A-1) indicates that a static coefficient of friction of 1.1 would be needed to prevent slip.

Finally there have been many friction measurements made of flooring surfaces (section D). Unfortunately the only fundamental evaluations of the static coefficient of friction have been made with the James machine and thus were made on flooring materials, not floors, and under controlled laboratory conditions, not in the field. Most field measurements have been made with either pendulum devices, such as the Sigler or the British Portable Skid Tester or with drag type devices such as the Horizontal Pul1 S1 ipmeter. 
- There are several industries interested in the leqal aspects of floor slip-resistance; the flooring manufacturers, the shoe manufacturers, the underwriters who insure buildings and the floor wax and polish manufacturers. Out of this interest have developed several papers on the leqal aspects of floor slip-resistance (F-5, F-9, F-22); the development of several floor slip-resistance testers, the James machine and the Horizontal Pull Slipmeter; and the development and promulqation of slipresistance standards. In addition the government, the Department of Defense as well as the General Services Administration, has been interested in the development of slip-resistance specifications.

The government specifications have been primarily developed by the military (F-6, F-10, F-11, F-12) and are quite stringent, requiring that $\mu$ be as high as 0.7 in some cases. The other major contribution to floor slip-resistance specifications has been a combined effort of Committee 021 of ASTM and the Scientific Committee of the Wax Division of Chemical Specialties Manufacturer's Association (CSMA). There has been considerable commen membership in these two bodies and a areat deal of cooperation between them. Merscher's paper (F-8) nicely summarizes their efforts, culminating in the recently published revision of "Standard Method of Test for Static Coefficient of Friction of Polish Coated Floor Surfaces as Measured by the James Machine" D2047-75. This version now' states "Floor polishes having a coefficient of static friction, as measured by this method, of not less than 0.5 traditionally have been recoanized as providina nonhazardous walkway surfaces. This value of not less than 0.5 meets the requirements for compliance to Rule 5 on 'The use of terms slip retardant, slip resistant or terms of similar import, ' of the Proposed Trade Practice Rules for the Floor Wax and Floor Polish Industry as issued by the Federal Trade Commission on March 17, 1953." 

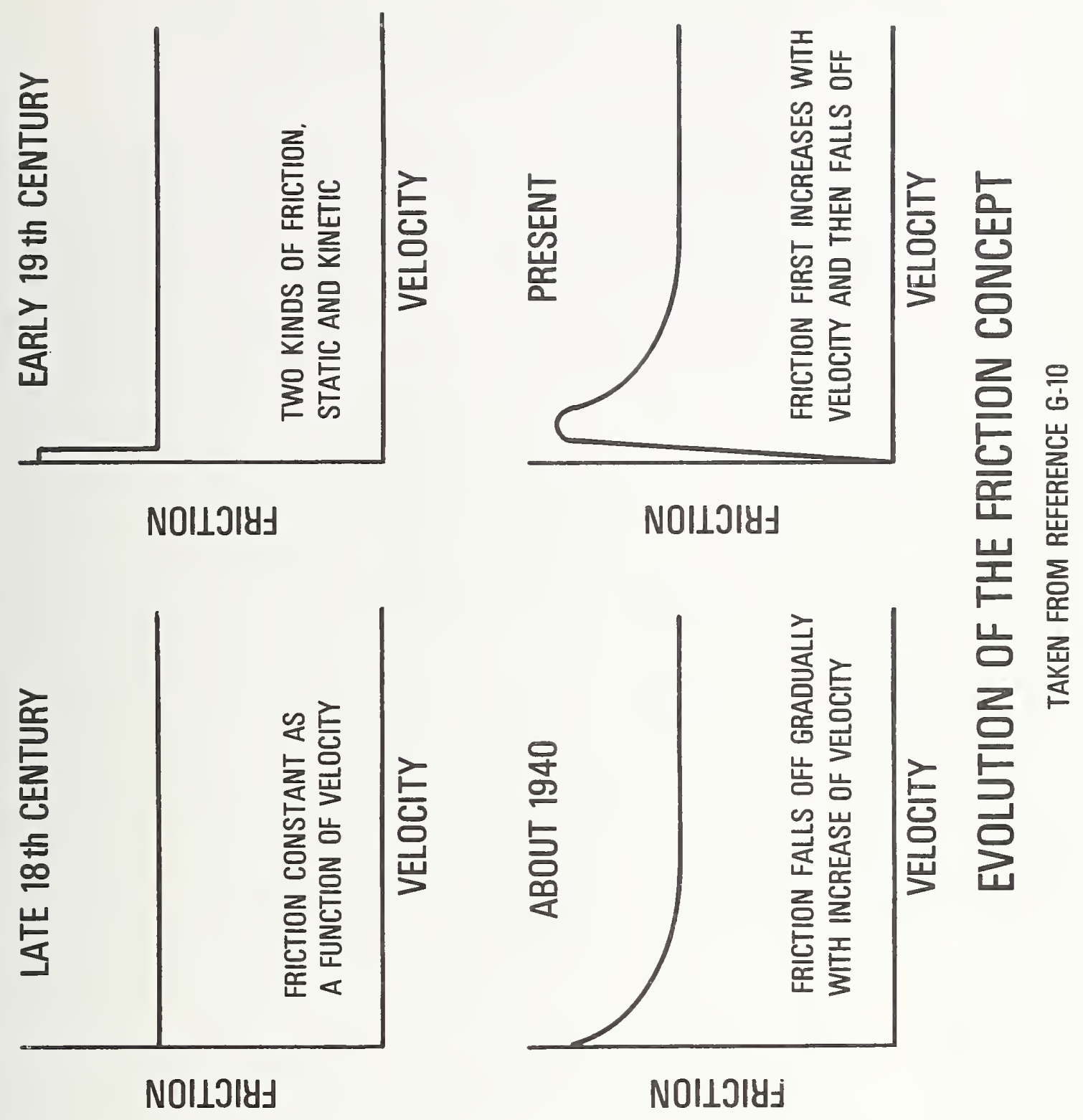

Finure 1 


\section{An Annotated Bibliography on the Slip-Resistance of Floors}

The discussions of, and direct quotations from, the entries have been limited to those relating to the subject of the slip-resistance of floors even though many of the entries, such as those on friction, have a much broader coverage.

The designation numbers, A-1 etc., are used for reference in the text as well as cross referencing in the bibliography. 
ANALYTICAL DETERMINATION OF THE REQUIRED MINIMUM VALUE OF COEFFICIENT OF FRICTION NEEDED FOR SAFE WALKING

CONSIDERING ANTHROPOMETRY AND KINESIOLOGY

A-1 Barrett, G. F. C. "Observations on the Coefficient of Friction of Shoe Soling Materials," Rubber Journal, Dec. 1, 1956.

Nice analytical development of the required $\mu$ for walking $>0.497$ or running $>1.077$. In both cases an estimate of the acceleration forces is included. A typographical error but not significant to the results.

\begin{tabular}{|c|c|c|}
\hline Static $\mu$ & Dynamic $\mu$ & Classification \\
\hline above 1.1 & $\begin{array}{l}>\text { static } \\
<\text { static } \\
=\text { static }\end{array}$ & $\begin{array}{l}\text { safe and rising } \\
\text { safe but falling } \\
\text { safe }\end{array}$ \\
\hline $0.5-1.1$ & $\begin{array}{l}>\text { static } \\
<\text { static } \\
=\text { static }\end{array}$ & $\begin{array}{l}\text { potentially safe } \\
\text { potentially slippery } \\
\text { intermediate }\end{array}$ \\
\hline below 0.5 & $\begin{array}{l}>\text { static } \\
<\text { static } \\
=\text { static }\end{array}$ & $\begin{array}{l}\text { slippery but rising } \\
\text { slippery but falling } \\
\text { slippery }\end{array}$ \\
\hline
\end{tabular}

Developed a neutrally suspended table to measure $\mu_{s}$ and $\mu_{d}$. Used an 11\# wt. on a $2 " \times 4$ " specimen yielding a pressure of $2 \mathrm{oz} / \mathrm{in}$. $^{2}$ Found no change in results for higher pressures up to $10 \mathrm{\# /} \mathrm{in.}{ }^{2}$ = approx. pressure for a man's foot.

Velocity of movement not controlled.

Surface tested dry and with a layer of water.

On dry surfaces leather is slippery but rising except on smooth concrete and polished linoleum, wetting the walking surface improves $\mu$

On dry surfaces rubber is safe or potentially safe, more variation on wet surfaces; potentially slippery on stone, concrete, and varnished wood.

On dry surfaces crepe rubber is safe, but intermediate or potentially slippery on most wet surfaces.

Resin rubber and microcellular rubber is slippery or potentially so on wet surfaces.

Much more variation among sole materials on dry surfaces, wetting tends to make them perform more nearly alike and on frozen surfaces everything is equally slippery. 
Although natural rubber has higher $\mu_{s}$ both wet and dry than leather the significant decrease of $\mu_{s}$ when wet for rubber, and increase for leather may make leather less likely to yield surprises.

"An ideal general purpose soling material might thus have a coefficient of static friction between 0.6 and 0.7 and a coefficient of dynamic friction between 0.7 and 0.8 under a 11 normal dry and wet conditions."

A-2 Ekkebus, C. F. and Killey, W., "Measurement of Safe Walkway Surfaces," Soap/Cosmetics/Chemical Specialties for Feb. 1973.

Good brief description of the mechanics and biology of walking.

Review of the history of $\mu \geq 0.5$ requirement. Theoretical justification, using anthropometry, of 0.5 as being a conservative but reasonable restriction on $\mu$ to provide slip resistant surfaces; based on leg lengths and stride lengths of a group of 16 people that were studied. They would have to execute an unnaturally long stride to slip on a 0.5 floor during normal walking.

Supports the use of the James Machine. "The swinging pendulum type of machine does not measure static $\mu$. These machines measure dynamic energy absorption which, by calculations, can be converted to dynamic $\mu$. It has been suggested that a dynamic $\mu$ measurement is needed to relate to people moving across.a floor. However, the foot is static in relation to the floor in walking. A dynamic measurement would only be valid after the foot has started to slip and therefore, cannot relate to normal walking conditions."

This paper is also available in a preprint form and as part of the Proceedings of CSMA 57 th mid-year meeting, May 1971. 
A-3 Schuster, K. "Slip - An Investigation of Practical Accident Prevention," Die Berufsgenossenschaft/Betriebssicherheit/ September 1966.

Accident statistics for one year 2,508 falling accidents $93 \%$ $(2,340)$ occurred on 1 evel ground, the rest on stairs. For accidents on level ground, slip or slipperiness was usually considered the most important factor.

Author rejects tests with live people as being unsafe and eliminating the element of surprise.

Uses a mechanics study instead. "It is hardly necessary to mention that the slip resistance necessary for safe movement is a function of this angle of contact. The smaller the angle of contact the larger the required slip resistance. On ice we use only an angle of contact which is very close to the vertical, since only a small slip resistance is necessary. If we want to slide, however, we make the angle of contact smaller. "The slip resistance is almost identical with the physical word friction." Then gives the few exceptions, like walking in sand. Then a discussion of which friction, static or dynamic or rolling. "Moving friction is only of secondary importance for normal propulsion. This result was obtained by comparing the length of the sole of a walking or running person with the length of the sole imprint on the floor. The greatest difference in size, if at all noticeable, measured only a few millimeters. Running friction therefore is only important when the static friction is not sufficient or in other words when the foot is already slipping -when safe locomotion becomes impossible. For practical accident prevention it is therefore sufficient to consider only or at least mainly, the static friction." 
Then makes a static analysis including centrifugal forces from curve negotiations. Argues that dynamic forces are small except at start or stop and then are compensated for by shortening steps and increasing contact angle. While walking a constant speed, dynamic forces are counteracted by counter accelerations of arms etc. While walking, angle of contact $=67^{\circ}$ corresponding to crotch or walking angle of $45^{\circ}$. While running rear contact angle becomes $60^{\circ}$ and forward contact angle approaches $90^{\circ}$. Finally finds that $\mu_{s} \geq$ 0.6 is necessary for safety in running around a curve of 3 meter radius at 3 meters/sec. which is equal to double walking speed. This results in $\mu$ only about $5 \%$ greater than that required for straight walking. Concludes that slip is not an important factor on stairs because both legs are nearly vertical when there is very much weight on them.

Then describes a tester, a more sophisticated version of the technical products tester. The use of this tester investigating many cases of slipperiness complaints showed that a slipperiness complaint was always for $a \mu_{s}<0.6$ and if $\mu_{s}>0.6$ there was a feeling of safety. Found that $\mu_{s} \geq 0.6$ on inclined planes resulted in safe walking up and down $15 \%$ grade and safe running up a $7 \%$ grade. Stresses the need to make measurements in the field. Describes two versions of the tester, one with a scale to yield $\mu_{s}$ directly, and one with a go, no-go pair of lights. Both versions incorporate an electronic readout. 
EXPERIMENTAL STUDIES OF KINESIOLOGY OR HUMAN LOCOMOTION, WITH SPECIFIC MEASUREMENT OF NORMAL AND TANGENTIAL FORCES SO THAT LIMITING VALUES OF COEFFICIENT OF FRICTION CAN BE ESTABLISHED

B-1 Amar, J. "Trotto ir dynamographique," Compt. rend., Acad. d. Sc. 163:130-132, 1916.

Vertical force, lateral shear and fore and aft shear of floor reaction on foot measured by a force plate. Mechanical devices using spring deflection.

B-2 "Complex Analysis Produces 'Signature' of Human Step," Product Engineering, July 1, 1968.

A general discussion of some force plate tests made at the Picatinny Arsenal, Dover, N. J., for the purpose of improving land mines. They used a force plate similar to that of Bresler and Franke1, C-6 plus some photocells to measure velocity. Only two subjects were tested and they were instructed to contact the force plate with either the heel or the sole but not both. Only one set of curves is presented but these are similar to other investigations and clearly show that the lateral forces do not assume significant values until the vertical forces are nearly a maximum.

B-3 Cunningham, D. M., "Components of Floor Reactions During Walking." Prosthetic Devices Research Project, Institute of Engineering Research, University of California, Berkeley. Advisory Committee on Artificial Limbs, National Research Council, Series II, Issue 14, November 1950.

A series of charts that extends the data of "Fundamental Studies of Human Locomotion and Other Information Relating to Design of Artificial Limbs." June 1947 report to Committee on Artificial Limbs of 
the National Research Council (B-8). Major extension is to measurement on a ramp. Shows that variation of normal force is only slightly out of phase with tangential force. Generally they increase and decrease together. When fore and aft shear is at a maximum normal force is just a little over half maximum when heel is being placed and just a little less than full maximum when toe is about to be 1 ifted.

Normal subjects walking level

Normal subjects walking upstairs

Normal subjects walking downstairs

Normal subjects walking up ramp

Normal subjects walking down ramp $\mu$ req

$\begin{array}{ll}\mu \text { req } & =.25-.33 \\ \mu \text { req } & =\leq .15 \\ \mu \text { req } & =\leq .15 \\ \mu \text { req } & =\leq .3 \\ \mu \text { req } & =\leq .4\end{array}$

Lateral shears are generally less than half the fore and aft shears.

Similar results for amputees, more variation among subjects.

B-4 Cunningham, Don M. and Brown, Wayne G., "Two Devices for Measuring the Forces Acting on the Human Body During Walking," University of California, Berkeley, Proceedings of the Society for Experimental Stress Analysis, Vol. 9, No. 2, 1952.

Describes a load measuring pylon which was substituted for the shank of a prosthesis and a force plate which measured the floor reactions on a normal or artificial foot. Only a few results reported to properly discuss the devices.

B-5 "Electronic Step-Meter Reveals Mechanics of Walking." National Bureau of Standards Technical News Bulletin, 1951, 35(4), 50.

Plate similar to the Berkeley plate, described in $\mathrm{C}-6$, but instrumented with springs and electronic mutual-inductance micrometers. 
Limited test results reported but statement that a minimum $\mu$ of 0.2 is essential if slipping is to be avoided.

Actually the single plot in the article of $V$ vs. time, $H$ vs. time and $H / V$ vs. time shows that $\mu \geq 0.2$ is essential in the initial part of the step (on the heel) and $\mu \geq 0.4$ becomes necessary for the latter part of the step, (on the toe). The published results were for a 247\# 6'4" man wearing shoes with large rubber lugs on soles and heels, but the article indicates that the other 12 subjects, ranging from 107-247\#, 5'2" - 6'4", 27-60 yrs, and both men and women were similar. The women had low, medium and high heels and the foot wear included rubber and leather heels and soles.

B-6 Elftman, Herbert, "The Measurement of the External Force in Walking," Science 88:152-153, 1938.

Mechanical, spring balanced, force plate to measure three components of the floor reaction on the foot; vertical force, lateral shear, fore and aft shear.

As reported in B-4 "Dr. Elftman's force plate was probably the most direct and accurate device for measurement of forces. However, its accuracy was limited by relatively large deflections of the walking surface and by the inertia of the plate and friction in the recording linkages." Also see following references.

Elftman, Herbert, Anatomical Record, Vol. 59, p. 481 (1934)

Elftman, Herbert and Manter, J., Science, Vo1. 88, p. 152 (1938)

Elftman, Herbert, Arbeitsphysiologic, Vol. 10, p. 485 (1939) 
B-7 "Fundamental Studies of Human Locomotion and Other Information Relating to the Design of Artificial Limbs." University of California, report to U.S. National Research Counci1, 1947.

Referred to in B-8 as having a detailed bibliography on dynamics of the human body. This material was intended to improve the design of artificial legs and concentrated on the study of the relative movement of the various parts of the body (particularly legs) and contributes little to the study of slip or other relative movement of the leg and the floor. However, in chapter IV, "Locomotion Study Using Interrupted Lights," there are several lapsed time photographs and diagrams that show there is little if any, relative movement of the foot and the floor while the foot, or any part of it is in contact with the floor, thus there is no slip shown during walking. This indicates that the dynamic is not the most significant with respect to walking. The Glass Walkway Studies of Chapter $V$ also show that there is little if any slip occurring during normal walking. Only studies of walking, level floor, stairs, ramp, with and without prostheses. No data on running. Chapter 8, "Force Plate Studies," gives data of most value to the study of floor slipresistance. Both the vertical and the fore and aft shear loads are given in terms of \% of body wt. and maximum values of both kinds of loads are given. However, no direct data on both loads at a common time are reported. Thus it is difficult to establish the value of $\mu$ needed.

However, this is no doubt the same or similar data reported in B-3 and B-4 so that the limiting value of $\mu$ developed is 0.4 , when descending a ramp. A fairly detailed study of the curves of forces versus time reveals that $\mu$ of as much as 0.5 might be needed just after the heel comes in contact with the floor and while the heel is tending to oppose forward motion. 
Center of pressure data demonstrates that normal walking has the center of pressure progressing more or less uniformly from back of heel to ball and toe of foot, and staying in vicinity of ball and arch when ascending or descending stairs. Rotation of the various segments of the $1 \mathrm{imb}$ about the long axes as revealed in Chapters I, "Study of Rotation During Locomotion, Using Pins," V, "Glass Walkway Studies," and VIII, "Force Plate Studies" is believed to be of major importance for normal gait, and finally is manifested by the torque developed in the force plates. It may very well be that the upper limit for $\mu$ may be dictated by the limit of torque permissible which will overly restrict their rotation. It may equally as well be that there must be sufficient $\mu$ to develop the torque needed to generate these rotations.

There is data to demonstrate that there is or needs to be some twisting slip between the foot or shoe and the floor, at least for normal walking in a straight line at any rate. "The $1 \mathrm{imb}$ is wound up, as it were, about its long axis in a medial direction to be suddenly unwound in the opposite direction at the completion of the phase of full weight-bearing."

B-8 Harper, F. C., Warlow, W. J. and Clarke, B. L. "The Forces Applied to the Floor by the Foot in Walking, "National Building Studies Research Paper \#32, Department of Scientific and Industrial Research Building Research Station, London 1961.

Interested in shoe wear, thus studied forces, concentrated on $H, V$, and $H / V=\mu$. Plate much 1 ike that of reference $B-4$.

Measured contact areas by photographing thru a glass plate. $H$ is resultant of a 11 components in plane of floor. Maximum H/V occurs as toe is about to leave the floor. Studied straight walking and 
walking around a corner, a right angled corner. Limiting values of H/V for 87 males and 37 females were obtained statisticaliy by using Pearson curves at the $1 / 1,000,000$ point and the incomplete $\beta$ function.

The limiting values of $H / \mathrm{V}$ obtained were 0.36 for straight walking, 0.40 for turning on the left foot and 0.36 for turning on the right foot. Actualiy only the 87 male subjects were analyzed statisticaliy because of the larger sample, but in general the female tests resulted in lower or comparable values of $H, V$, and $H / V$. Max. foot pressure 7-44 psi., max. heel pressure 14-840 psi. 
C-1 Abrahamson, E., "Zur Kenntnis der Mechanik des Mittelfusses," Skandinav, Arch. F. Physical. 51: 175-234, 1927.

Studied pressure distribution on the foot using steel shot pressed against a lead plate.

C-2 Basler, A., "Kinematographische Aufnahmen mit gleichzeitiger Registrierung von Kraeften," Arbeitsphysica7. 8: 585-590, 1935.

Pressure on small areas of the foot was determined using a series of parallel rods.

C-3 Basler, A (1936) - Abderhalden. "Handbuch der biologischen Arbeitsmethoden." Abt. V. Organfunktionen. pp. 559-74. (Urban and Schwarzenberg: Berlin).

Indicates that results are not for subjects normally shod walking on ordinary floors.

C-4 Beely, F., "Zur Mechanik des Stehens," Arch. f. K1in. Chir. 27: 457$471,1882$.

Studied pressure distribution on the foot using plaster-of-paris impressions.

C-5 Bernstein, N. A. and others, "Biodynamics of Locomotion," Vo1. 1, Moscow, 1935.

An extension and improvement of Fischer's technique and evaluation of results (see C-14 and 15). 
C-6 Bresler, B. and Frankel, J. P. "The Forces and Moments in the Leg During Level Walking" Transactions of the ASME Vol. 72, No. 1, January 1950.

An excellent discussion and bibliography on the Human Gait. Gives no indication that there is any data on the forces between foot and floor in their papers. The early investigators had no satisfactory way to measure forces and thus their work is largely confined to the study of chromophotography and other techniques for analysing the kinematics of human locomotion. Only Elftman, (B-6) measured forces and his device generally permitted such large displacements as to bring Heisenberg's uncertainty principle into play. Paper shows a few results of force plate measurements but there is much more data in B-7, B-3 and B-4.

C-7 Bresler, B. and Berry, F. R., "Energy Characteristics of Normal and Prosthetic Ankle Joints," Prosthetic Devices Research Project, Institute of Engineering Research, University of California, Berkeley, Advisory Committee on Artificial Limbs, National Research Council, April 1950.

Experimental study of several artificial ankle joints.

Seems to be of little value to the study of floor slipperiness.

C-8 Bresler, B. and Berry, F. R., "Energy and Power in the Leg During Normal Level Walking," Prosthetic Devices Research Project, Institute of Engineering Research, University of California, Berkeley, Advisory Committee on Artificial Limbs, National Research Council, May 1951.

Only very indirectly related to the study of floor slipperiness. 
C-9 Carlet, M. G., "Essai Experimental sur 1a Locomotion humain, Etude de 1a Marche." Ann. d. Scien. mat. Zojol. 16:1-92, 1872.

First measurement of the vertical force on the foot, using a pneaumatic cell in the sole of the shoe.

C-10 Carlsöö, Sven "How Man Moves, Kinesiological Methods and Studies," Heinemann:London, 1972.

A brief but thorough treatment of the subject including description of the various experimental devices used. Chapter 5 "The Gait" and a portion of chapter 7 "Kinesiological Analyses in Sports and Work" on "slipping and the risk of slipping in the factory" are of most interest to the researcher in floor slipresistance.

Fig. 41, "Schematic representation of the pattern of movement of certain body parts in walking projected in the sagital plane," presumably obtained from chromocyclographs, shows no slip between the foot and the floor.

From chapter 7 "Slipping is one of the most common causes of accidents on the job. It is particularly in the food industry and food trades that such accidents are serious, elusive problems.

"However, considerable efforts have been made in recent years to prevent these accidents. In this context, studies have been made of the friction between footwear and floor under various conditions. A consistent finding has been that the friction which exists prior to the slip is of critical importance for the occurrence of slipping. Thus, static friction is the critical value." 
A nice succinct discussion of friction, including the point. "The frictional force may also be independent of the normal force if there is a liquid between the slip surfaces and if the rate of slip is low -- only low rates are involved in the present context. In physics this is known as fluid friction and the frictional force is considered to be proportional to the rate of slip."

Reports tests of about 100 persons when $H$ \& V were measured with a force plate as a function of time. Then $H / V$ was calculated and plotted as a function of time. Maximum values of $H / V=f e$, and thus the greatest likelihood of slip occurred at the start and the end of the step. $f_{e}$ is the required static coefficient of friction to prevent slip and for the 100 subjects had a mean value of 0.23 .

Describes an "artificial lower leg with heel," attached to a three wheeled cart used to measure static friction between heels and floors. The angle of attack of the heel could be varied independently of the angle of the leg which was set at some fixed value before each test. Thus the evaluation of a single location on a floor required the conduction of several tests, each with a different length of leg and resultant angle of inclination of the leg. The device was developed because they found existing devices to have the following shortcomings: "In the first place, it is not at all clear which magnitudes characterize a risk of slipping and what the measurements imply in purely physical terms. In the second place, most of the measurements can only be made in the laboratory and not at places of work, while in the third place many of the methods do not give reproducible measurements and consequently call for statistical processing of a series of data."

Using a rubber heel on the above mentioned device, measurements were made in a meat factory. They found that $f=\mu_{s}$ varied from a 
low of 0.10 in front of a preserving table to a high of 0.64 near the mixer. They judged that the risk of slipping was very great where $\mu_{s}<0.30$ and practically non-existent where $\mu>0.50$.

Some additional tests were made under more controlled conditions using both wooden and rubber heels with similar results. A wooden heel was found to be "safer" when wet than when dry, but as is the case with most testers, there was an opportunity for water to be extruded from beneath the heel before the test commenced.

C-11 Carlsöö, Sven, "A Method for Studying Walking on Different Surfaces." Merely describes a force plate and their initial efforts at using it. No results as yet available.

A nice description of the human gait. "In the human gait the equilibrium is lost and regained with every step; lost with the take off of the propelling foot when the body's center of gravity momentarily lies beyond the anterior border of the supporting surface. It is regained as soon as the swinging leg is extended forward and its heel touches the ground. The horizontal component of the force applied by the foot when it touches the floor acts forward and is counteracted in ordinary walking by a friction force which is just as large but acts in the opposite direction. It is this play of forces which reestablishes the momentarily lost balance at each step. But if the friction force is less than the horizontal force applied by the foot, the foot skids along the floor and we slip."

C-12 Elftman, Herbert; "A Cinematic Study of the Distribution of Pressure in the Human Foot," Anat. Rec. 59:481-490, 1934.

Studied pressure distribution on the foot using photographic means. 
Includes a summary of previous work. C-17 indicates that these tests are not on subjects normally shod walking on ordinary floors.

C-i3 Elftman, H. (1939) -- Amer. J. Physiol. 125:339-56.

C-17 indicates that results are not for subjects normally shod walking on ordinary floors.

C-14 Fischer, 0., "Der Gang des Menschen, I. Thiel:

Versuche am unbelasteten und belasteten Menschen, Abhandlungen der Mathematisch - Physischen Classe der Königlich Sächsischen." Gese11schaft der Wissenschaften. Classe 21, p. 153-322, Leipzig, 1895.

C-15 Fisher, 0., "Der Gang des Menschen, II. Thie1: Die Bewegung des Gesammtschwer punktes und die äusseren Kräfte, Abhandlungen der Mathematisch - Physischen Classe der Königlich Sächsischen." Gese11schaft der Wissenschaften. Classe 25, p. 3-130, Leipzig, 1895.

B-4 refers to this as follows: "The forces acting on the body have also been determined indirectly from three dimensional space-time relationships for the various body segments. In 1895 Fischer determined these relationships for the component parts and the center (of) (sic) gravity of the body as a whole. A thorough analysis of one subject was made by means of still photographs taken while Geisler tubes fastened to the body segments flashed intermittently. Fischer's work still remains the classical example of the method."

C-16 Fung, Y. C. \& Anliker, M. "Biomechanics, Its foundations and Objectives," edited by Y. C. Fung and M. Anliker. Published by PrenticeHa 11, Inc., Englewood Cliffs, New Jersey, 1972. 
This volume is the edited symposium on Biomechanics, Its Foundations and Objectives, which was held in La Jolla, California, from July 29 to 31, 1970. This Symposium was sponsored by the University of California, San Diego, and the United States Navy, Office of Naval Research.

This symposium is a series of papers, only one of which appears to be of any value to floor slip-resistance, paper \#20 entitled, "Biomechanical Compatibility of Prosthetic Devices," by J. P. Paul, J. Hughes, and R. M. Kenedi.

This is a rather brief paper, but does a nice job of covering the mechanics of prosthetic devices, primarily legs. However, it pretty much limits itself to the forces or pressures that occur within the joint, rather than the forces that occur between the foot and the floor. Thus, it is of limited interest to floor slipperiness.

C-17 Holden, T. S., and Muncey, R. W., "Pressures on the Human Foot During Walking," Aust. J. App. Sci., 1953, 4(3) 405.

Used a pressure sensitive cell in the shoe, thus measured only the vertical component. Thus of little value in studying the friction requirements of the floor surface.

"Instantaneous pressures developed on the sole of the foot during walking in ordinary shoes on any floors can be measured with the equipment described. Large variations in the shape of the pressuretime curve occur from one person to another, but the step-to-step variations of any one person are very much less. Variations in the rate of walking changes the ordinates and abscissae approximately in inverse proportion. Variations due to changes in floor surface 
are almost nonexistent, the only noticeable effect being the disappearance of a small impact peak when the subject changes from ordinary floors (concrete, wood) to lawn."

Referenced in D-8 and quoted that "A study conducted by Holden \& Muncey showed that pressures exerted on the heel by most of the subjects in walking ranged from 20 to 30 pounds per square inch with an overall average of 25 pounds."

C-18 Klopsteg, P. E., Wilson, P. D., et al. Human Limbs and Their Substitutes. New York, 1954, McGraw Hi11.

Referred to in B-8 as having a detailed bibliography on dynamics of the human body.

C-19 Marey, E. J., "De 1a Locomotion terrestre chez les bipedes et les quadrupedes," J. de L'Anat, et de 1a Physiol. 9:42-80, 1873.

One of the first examples of the measurement of the vertical force on the foot, using a pneumatic cell in the sole of the shoe.

C-20 Rehman, I. (1947), - Arch. Phys. Med. 28:749-56.

C-17 indicates that results are not for subjects normally shod walking on ordinary floors.

C-21 Schwartz, R. P., Heath, A. L., and Wright, J. N. "Electrobasographic Method of Recording Gait," Archives of Surgery, Nov., 1933, Vol. 27.

C-22 Schwartz, R. P., Heath, A. L., Miziek, W., and Wright, J. N., "Kinetics of Human Gait" The Journal of Bone and Joint Surgery, Vol. XVI, No. 2, Apr., 1934. 
C-23 Schwartz, R. P., and Heath, A. L., "The Definition of Human Locomotion on the Basis of Measurement." (1947) The Journal of Bone and Joint Surgery, 29: No 1, 203-14., Jan. 1947.

Discusses the workings of an oscilloscope designed and built in 1939 and the home-made piezoelectric pressure gages. They used individual gages to measure the pressure or force at six distinct locations on the plantar surface of each foot. Found that in spite of the fact that individuals can often be recognized by the sound of their gait, normal gaits are remarkably similar and in fact vary no more from person to person than from time to time for the same person. By summing the six individual traces to a single line plot they got the same double humped curve as have other investigators, such as the Berkeley group. They reported several infirm gaits as well as the normal ones. No measure made of $H$ so that $H / V$ could not be considered. They put the lie to the concept of everyone walking differently.

C-24 Schwartz, R. P.; Heath, A. L.; Morgan, D. W. and Towns, R. C.; "A Quantitative Analysis of Recorded Variables in the Walking Pattern of 'Normal' Adults," The Journal of Bone and Joint Surgery, Vol. 46A, No. 2, pp. 324-334, March 1964.

Presents data similar to that of $\mathrm{C}-23$ on three men and one woman. Again shows that there is as much gait variation with time for one person as there is among different "normal" people; particularly when speed of gait or height of heel, for a woman, is varied. Thus in spite of the fact that we can sometimes recognize certain gaits by sound there is really very little difference between "normal" gaits. No measurement of $H$ so that $H / V$ cannot be considered. 
C-25 Steindler, A., "Mechanics of Normal and Pathological Locomotion in Man," by Arthur Steindler, M.D. F.A.C.S., Professor of Orthopedic Surgery, State University of Iowa, Iowa City, Iowa. Published by Charles C. Thomas, Springfield, Illinois, and Baltimore, Maryland, 1935.

Referred to in B-8 as having a detailed bibliography on dynamics of the human body.

Chapter 27 entitled, "The Mechanics of the Human Gait," and Chapter 28 entitled, "Graphic Description of the Gait," is pretty much the same material as appears in Steindler's more recent book, C-26.

C-26 Steindler, A. "Kinesiology, of the Human Body, Under Normal and Pathological Conditions," by Arthur Steindler, M.D. (Hon.) F.R.C.S., Eng. F.A.C.S., F.I.C.S., Professor Orthopedic Surgery, Emeritus, State University of Iowa, Head of Orthopedic Department, Mercy Hospital, Iowa City, Iowa. Published by Charles C. Thomas, Springfield, I1linois, 1955.

There is an interesting, but somewhat sketchy, historical treatment up to the early fifties on the mechanics of the gait. It misses some significant references such as those of Sigler and others in the Nationa 1 Bureau of Standards. In his discussion of alternating bipedalism, which follows his discussion of first the quadrupedal gait and then bipedalism in general; he states "the human gait, therefore, can be described as an alternating play between the two extremities, one in touch with the ground producing in sequence restraint and propulsion, while the other swinging freely carries with it the forward momentum of the body. At the completion of the swing the leg again touches the ground, first restraining the body in its forward path and then again assuming the role of propulsion. The moment the center of gravity of the forward moving body has 
passed beyond the supporting base the balance is lost and remains lost during the entire propulsion phase of the standing leg. It is only regained as the heel of the other leg touches the ground and the leg exercises a restraining function. It is quite proper, therefore, to designate the human gait as a constant play between loss and recovery of the equilibrium."

He gives no credit to this statement and thus it would seem that it is original with him. This statement is, however, quoted, usually without credit, by many later authors.

The remainder of this chapter which he entitles "Lecture 37 on the Mechanics of the Gait," pretty much describes the kinematics; that is the displacement, velocity and acceleration. He uses fairly primitive ways to get the velocity and acceleration; by differentiating the displacement curve to get the velocity curve and in turn differentiating that to get the acceleration curve.

Differentiating experimental curves generally leads to sizeable inaccuracies. There are no direct measurements of forces or pressures, although he does make some calculations of the work done during movement.

C-27 Strasser, H., Lehrbuch der Muskel und Gelenk Mechanik, 4 Vols, Berlin, 1908-17.

Referred to in B-8 as having a detailed bibliography on dynamics of the human body.

C-28 Sussman, A., and Goode, R., "The Magic of Walking."

Delightful treatment of walking describing its history, its benefits, its proponents and places to do it. 
Chapter entitled "Engineer's Delight" states that the body is ideally designed only for walking, certainly not for sitting or standing. "Walking, the human design comes into its own. Form blends with function and the result is harmony and perfect performance. The body is built for action, and the action for which it is specifically built is walking.

"Consider what happens to the body structure when we walk. The flexible spine yields and springs back with each stride; the spring like forms of the arched feet dissipate the impact of weight meeting surface as effectively as any fluid suspensions designed by Genera 1 Motors engineers.

"And see what use is made of the body's peculiar distribution of weight. The top-heavy torso now reveals its true value in twolegged locomotion: The forward pull of its weight becomes the motive power for its progress. With each stride we are falling forward, and one or the other leg is swinging out on its bal1-andsocket hip joint to catch us.

"In terms of its mechanics, walking is nothing more than a series of stumbles caught in the nick of time, a continuous rythmic loss and recovery of balance. Gravitation, no less, is the force that we harness to our service when we walk.

"If we need any proof of this, we have only to remember that when the astronauts go 'walking' weightless in space, they need a little jet-propulsion gadget to move them - because they do not have the help of gravity."

Chapter 3 "Engineer's Delight" and Chapter 7 "The Science and Art of Walking" present excellent general descriptions of the mechanics of walking and are frequently stolen and/or referred to by other authors. 
Chapter 7 "to describe walking as a successive loss and recovery of balance is mechanically accurate, but it gives us the image of a herky-jerky gait that is nothing at all like the smooth flow of natural walking style. Our minds-eye picture is closer to the fact when we see it as a continuous ripple of motion flowing up and down through muscles and joints. From head to toes and back, without a break anywhere along the 1 ine.

"The motion is smooth because the succcssive transactions with gravity are bridged by forward momentum. The body moves flexibly, but all at once. To take a step, it tilts slightly forward, but not head and shoulder first, or abdomen first, or bent at the hips to push the torso ahead. It tilts forward by bending slightly at the ankles. Try it. Shift from an erect standing position to walking position in slow motion, and you will see that it is your ankles that tilt you forward, or rather the ankle of the standing foot, because the other is already lifting to take your weight in a forward step. The knee of the standing leg does not bend, but rather straightens, at the same time as the heel lifts and the foot muscles push off from the toe.

"The knee of the forward leg does bend, to lift and again to take the weight as it lands. In a good walking style, the body tilts forward just far enough to keep the center of gravity moving forward in the right mechanical relation to the individual's natural length of stride. We don't need a slide rule to figure this out. Fortunately because if we give it a chance the body figures it out pretty much for itself.

"Once the body finds its proper angle, it does not jerk forward and back with each stride. It keeps the angle unaltered within the fluid forward motion, as long as it is going along at the same pace and the ground is level." 
D-1 "Be11 System Practises, Measurement of S1ip-Resistance of Resilient Floors. Principles and Evaluation," section H51.119 (Aug. 1958) AT\&T Company Standard.

Describes an instrumented floor polisher used to measure slipperiness by AT\&T and Public Buildings Service, GSA.

D-2 Boone, T. H. \& Auld, C. W. "Standard Measurements of Slipperiness on Wal kway and Roadway Surfaces," Progress Report 1, NBS Report 7510, 21 May 1962.

Factors Affecting Friction of Rubber

Adhesion: Caused by intimate contact between the two surfaces at individual points. Thus proportional to the "actual" contact area which may be proportional to the "average" contact area.

Hysteresis: energy loss owing to the mechanical interaction of the surfaces. Proportional to the hysteresis value of the rubber and deformation it undergoes. Could be independent of contact area, for smaller areas more work per area because of increased pressures.

Cohesion: "It is likely that cohesion, as such, has very little effect on friction, but contributes indirectly by augmenting adhesion and hysteresis resistance." There may also be viscous drag in any lubricating layer that is present but "any viscous drag is also negligible if the lubricating film remains thick enough and the sliding velocity is not excessive." Then describes two models of the Sigler tester and the British Portable Skid Tester. 
Ran a series of tests comparing synthetic rubber and natural rubber sliders. "With the exception of the stainless steel surface, the SR sliders gave higher readings than the NR sliders," "on the steel surface, where the hysteresis and cohesive forces of the rubber were of less significance, the softer NR with its greater surface contact gave higher results." In addition to the stainless steel, an epoxy and three different concretes were evaluated.

In an attempt to establish reference surfaces for floors, six asphalt tiles, four vinyl asbestos tiles, cork, linoleum, cork/vinyl tiles and vinyl were tested dry and wet, unexposed and after exposure to four years of pedestrian traffic. All but one of the asphalts and all but one of the vinyl asbestos tiles showed reduced slip resistance caused by four years of wear. Generally the other materials showed increased slip resistance caused by wear. Finally 7 British Portable Skid Testers were compared and found to yield reasonably consistent results.

D-3 Braun, R. and Roemer, D. "Influence of Waxes on the Static and Dynamic Friction," Soap/Cosmetics/Chemical Specialties, Dec. 1974.

Reproducible results required replications \& statistics. In general polishes increased $\mu$, suggests an optimum value above which no gain and below which danger. "An analysis of the walking process shows that at the beginning and towards the end of a step, the horizontal force between the foot and the floor reaches a maximum. This has to be compensated for by the static friction. The dynamic friction is also important since it must prevent the sliding process from developing into slipping. ...We realize that other kinds of motion can bccur during running and walking; however, it is not practical to design a measuring procedure which will cover all cases imaginable. On plastic films as well as on floors, the friction does not follow the Coulomb-Amonton law which states that the frictional coefficients are not dependent upon the pressure of 
contact and the speed. In addition, a great number of other parameters, such as temperature and humidity are important, and static friction depends on the contact time which starts when the test shoe is placed on the floor and ends when the actual test begins." The James machine is unsatisfactory "since contact pressure is only approximated and the contact time prior to testing cannot be enumerated at a11." A device developed by K. Schuster consists of a sledge with a built-in dynamometer that is pulled over the substrate by hand. In this case, the test data are strongly dependent on the individual doing the testing. The Topaka is an improvement because of the motor drive. "With this device only the dynamic friction can be measured for reasons which will be obvious later on."

The Hoechst device, developed by Braun and Roemer, uses three symmetrically placed, chromium plated shoes that are mechanically lapped. $\mu_{s}$ occurs in the moment the shoe starts moving. This can be established when $\bar{a}, \bar{v}$ or $\bar{s} \equiv 0$. "However a simple calculation shows that $\bar{a}$ is most suitable to determine this moment." For example if $\bar{a}$ is proportional to $t$ then $\bar{v}$ increases as $t^{2}$ and $\bar{s}$ as $t^{3}$. Thus $\bar{a}$ at time $t=0$ is easiest to evaluate. It is necessary to measure $\mu_{s}$ a $\bar{a} \equiv 0$ since "when the movement starts, the mass force necessary for speeding up the shoe is measured in addition to the friction." They found that Fmax "near" the start of motion could be as much as twice the $F_{s}$ needed to initiate motion. This points up the need to have a fairly light shoe relative to the normal weight. The James device has this feature. "To determine dynamic friction, only the force necessary for maintaining constant speed has to be measured. There is a stick-slip problem, caused by small irregularities in the surface, causing oscillations in the force and speed. They are most noticeable at the start and tend to damp out. A non-elastic drive arrangement would help but would be hard to achieve. Another way to approach the problem is to average 
over a long period of time, by integration or by damping the oscil10graph." Got good reproducibility with chrome plated shoes, in contrast to leather, rubber or PVC. Normal foot pressure about 7 psi, but found that $\mu_{s} \& \mu_{d}$ varied very little in range of pressure of 3.6-7.3 psi, thus used about $3.5 \mathrm{psi}$. In general $\mu_{\mathrm{s}}$ increases slightly with $p$ but not with all polishes. $\mu_{s}$ as a function of $v$ is not very sensitive. A decisive quantity for $\mu_{S}$ is $t_{S}$, the standing time.

"One quantity which is decisive for the static friction is the standing time, $t_{s}$, between putting down the shoe on the substrate and the start of the test run. At first $\mu_{s}$ shows a remarkable increase with $t_{s}$ and reaches a limiting value only after a prolonged time." They used $t_{s}=1$ second.

Fairly sophisticated statistical analysis of data revealed the need to make 6 replications. Found that generally $\mu_{s}>\mu_{d}$ but only slightly, $\mu_{s} / \mu_{d}=1.1$. The substrate had a greater effect on $\mu_{s}$ or $\mu_{d}$ than the polish.

"Cases in which the dynamic friction exceeds the static friction essentially are only of theoretical interest since a high $\mu_{d}$ damages the polish-film during sliding."

D-4 Bunten, J. "Friction Measurements on Soles and Heels, With Particular Reference to Women's top-piece Materials," SATRA, Shoe and Allied Trades Research Association, SATRA House, Kettering, Northants SATRA Memorandum, T. M. 1355.

Nice general discussion of the problems of measuring friction of shoe soles and heels.

Claims $\mu$ varys with pressure \& velocity. Describes the SATRA ramp test for floor slipperiness, first reported in a SATRA bulletin for 
August 1950. Mentions many serious limitations, particularly that the natural action of walking on level ground is not closely reproduced particularly at the important instant when the heel first touches the ground. Describes devices of the same type as the Horizontal Pull Slip Meter and the British Portable Skid Tester. Results on clay quarry tiles are given, wet \& dry, on ramp, HPS \& BPST. "The differences between wet and dry conditions are most consistent for the BPST, with the wet friction always lower than the dry. The HPS method appears to give higher wet than dry $\mu$ for the hard materials and higher dry than wet for the soft. The ramp tests show no consistent difference."

Measurement on polished vinyl tiles, wet, using the BPST gave very low results on almost all materials tested. Apart from microcellular rubber, at 0.18 , a $11 \mathrm{\mu}$ 's were in the range 0.09-0.11. In other words this sort of surface can be dangerous in itself, whatever the soling and top piecing used.

D-5 "Coefficient of Friction (S1ip) Measurements," G-63-10 Fixture, Instron Corp., Canton, Mass.

D-6 Day, S. S. - Bowen, H. D.; \& Hader, R. J. "Skid Resistance of Floor Surfaces and Finishes" Resilient Floor Coverings, Hard Floor Surfaces and Wood Floor Finishes, Tech. Bul. No. 200, North Carolina Agricultural Experiment Station In Cooperation with the School of Home Economics. The University of North Carolina at Greensboro, Dec. 1970.

\section{Error in tables 13-16}

Extensive paper describing a series of MS theses that evaluated a series of floors \& shoe materials using the Bowen Friction Tester. The BFT is a table that rotates with several flooring surfaces under a shoe of any desired material. Based on results of a study 
at Michigan State the rotational velocity was such as to yield a linear velocity of $15 \mathrm{ft} . / \mathrm{min}$. at the shoe. Thus only a dynamic coefficient was measured. A "mechanical" recorder was used.

Investigation One: Various heel materials and new and worn resilient floor materials.

1. By far the biggest effect on $\mu$ is that of the heel material.

2. Second largest effect is condition of floor, $\mu$ generally being lower for worn floors. 


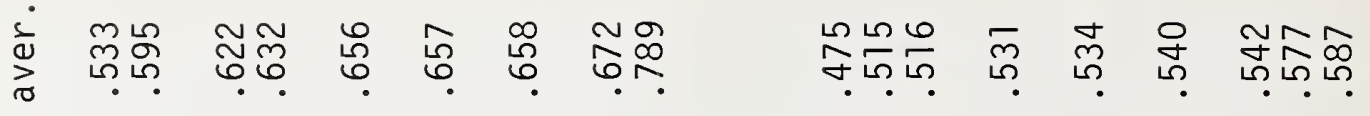

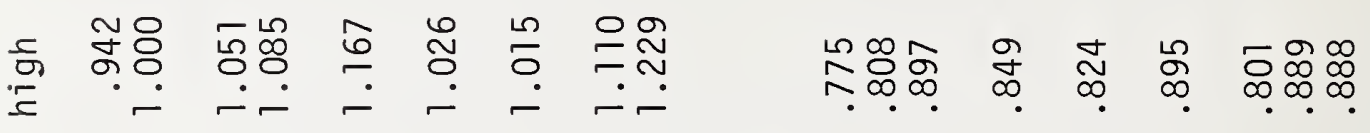

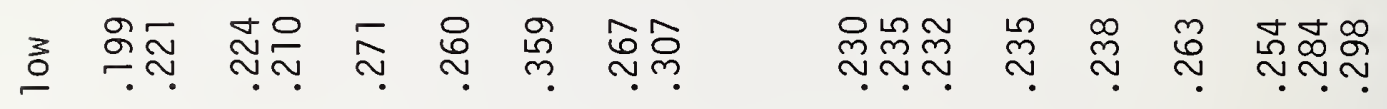

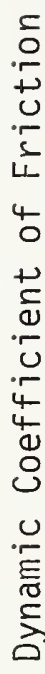

$\frac{\pi}{\pi} \quad \stackrel{2}{\pi}$

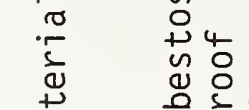

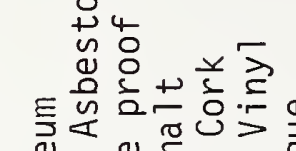

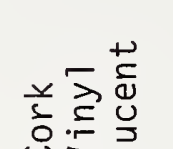

$\frac{2}{2}$

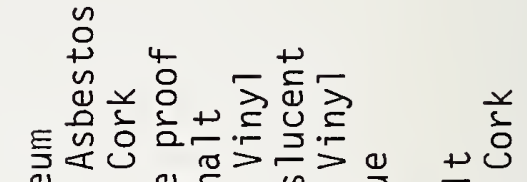

\& ब ब थ

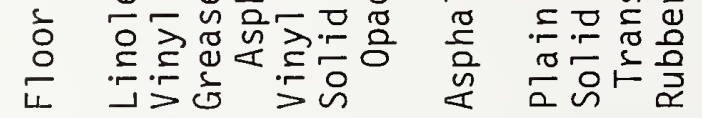

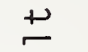

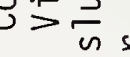

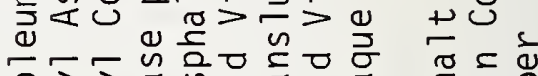

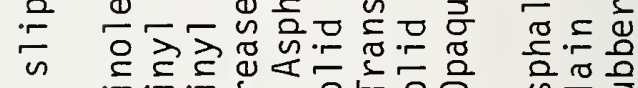

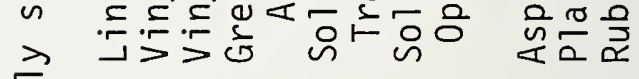

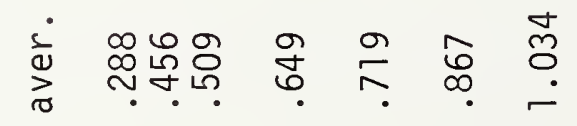

+1
$\frac{1}{8}$
0
$\frac{1}{4}$
$\frac{5}{0}$
$\frac{5}{4}$

๙

$\hat{\imath}^{\circ}$

톨

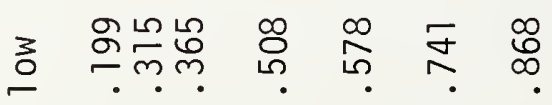

$\frac{1}{2}$
$\frac{2}{2}$
$\frac{8}{2}$
$\frac{1}{2}$
$\frac{1}{5}$

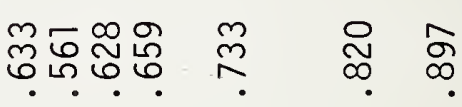

$\underset{\sigma}{\frac{D}{\sigma}}$

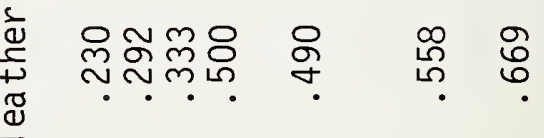

高

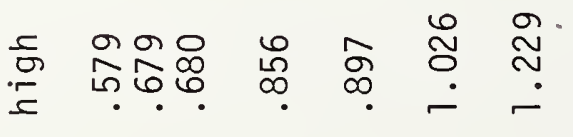

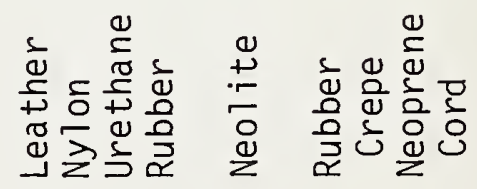

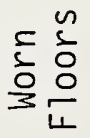


Investigation two: Effect of size of heel or normal load on the heel.

Four different heel sizes and five different surcharges were used, resulting in the following range of contact pressures.

load on heel

Hee 1 size, in. ${ }^{2} 5 \# \quad 11 \# \quad 18.5 \# \quad 26 \#$ 33.5\#

$\begin{array}{lrrrrrr}\text { Stacked } & 0.74 & 6.76 & 14.86 & 25.00 & 35.14 & 45.27 \\ \text { Cuban } & 1.50 & 3.33 & 7.33 & 12.33 & 17.33 & 22.33 \\ \text { Child's } & 5.23 & 0.96 & 2.10 & 3.54 & 4.97 & 6.41 \\ \text { Man's } & 10.00 & 0.50 & 1.10 & 1.85 & 2.60 & 3.35\end{array}$

For Leather $\quad .296 \leq \mu \leq .327$, for rubber $.516 \leq \mu \leq .716$

Rubber has a much higher $\mu$ than leather. Increasing weight increased $\mu$ for rubber but not for leather. Increasing heel size increased $\mu$ for leather and decreased $\mu$ for rubber.

Investigation Three: Three materials: Leather Nylon Rubber $\begin{array}{llll}\text { Av. } \mu & .245 & .567 & .605\end{array}$

and three manufacturers of each.

Material has the greatest significance, but material manufacturers and flooring materials have some significance.

Investigation Four: The effect of floor polishes in both dry and wet conditions on resilient floor coverings.

1. Heel materials show a greater effect on skid resistance than resilient floor materials or brands of floor polish, 
but interact with them. Low $\mu$ 's are obtained with leather and relatively high $\mu$ 's with rubber, neoprene-cord and crepe heels in a dry condition.

2. Moisture reduces $\mu$ for a 11 heel materials except leather and for a 11 floor materials, though for linoleum the reduction is sma 11 .

3. In a dry condition different floor materials exhibit different $\mu$ 's but not so when wet.

4. Both polish type and brands within polish type show significant differences of $\mu$, those within types only slightly smaller than those between types.

5. Dry tests showed skid resistant polish superior to ordinary \& clear polishes, but wet tests reversed the order of polishes in terms of $\mu$, ordinary-highest and skid resistant-lowest. Polished floors generally lower than bare floors \& worn floors.

\section{Investigation of Skid Resistance of Hard Floor Materials}

The rank order of the dry floor materials differed from that of the same materials wet; aggregate, glazed ceramic tile and concrete were best dry and poorest wet, while terrazzo, quarry tile and unglazed ceramic tile were poorest dry and best wet, as a class they decreased only $10-24 \%$ by wetting. Heel materials showed greater variation than floor materials or polishes, leather being poorest and crepe the best. $\mu$ for 1eather was $43-70 \%$ less than for other heel materials. Moisture reduced $\mu$ except for leather on quarry tile or unglazed ceramic tile; significantly so for all heels on concrete, aggregate or glazed ceramic tile. Polish reduced $\mu$ in all cases except terrazzo, dry. Type of polish had little effect dry but wet the skid resistant polishes were worst, compared to clear and ordinary polishes. Application of moisture reduced $\mu$ in all cases, particularly on polished floors. Wearing the floor tended to increase $\mu$ and polishing tended to decrease $\mu$, except for crepe soles. 
Heel material has the greatest effect, leather poorest, crepe best. On bare finishes moisture decreased $\mu$ except for penetrating seal. On dry wood flooring, all finishes, al1 heels except leather yielded $\mu \geq 0.40$ with moisture some were $<0.40$. Waxing lowered $\mu$ except for the self-polishing. H for bare and self-polishing was usually $\geq$ 0.50. Dry the paste. skid resistance was as good as self-polishing, but wet it was more 1 ike the other waxes. General1y $\mu \geq 0.5$ would pass most heels on most dry surfaces, but it would take $\mu \geq 0.2$ to pass leather heels on all dry surfaces and about half the wet surfaces.

D-7 Day, S. S.; and Hodges, M. B. "Factors Affecting Skid Resistance of Hard Flo.or Surfaces," Hospitals, J.A.H.A. April 16, 1967, Vol. 41.

This material is presented more completely in D-6 but there appears to be an error in tables 13-16 of D-6.

D-8 Day, S. S. \& Shamburger, E. "Factors Controlling Skid Resistance of Resilient Floor Coverings," Hospitals, J.A.H.A., Apri1 16, 1965, Vo1. 39.

Results reported in bar chart form that are also reported in tabular form in D-6. Heel material had greatest effect; for leather, dry \& wet, $0.15 \leq \mu \leq 0.40$, wet better than dry; for rubber dry \& wet $0.30 \leq \mu \leq 0.95$, dry much better than wet: $0.30 \leq \mu \leq 0.50$ wet $0.40 \leq \mu \leq 0.95$ dry

Skid Resistant polishes generally improved $\mu$ for leather dry, but in this one case leather wet showed a decrease in $\mu$. Skid resistant polishes also gave best $\mu$ for rubber dry but for rubber wet 
a 11 polishes were equally bad. For crepe $0.5 \leq \mu \leq 1.2$ dry, $0.15 \leq \mu \leq 0.8$ wet. Generally on dry floors, polish helps, skid resistant the most. On wet floors the polish frequently is more slippery than a bare floor, particularly for the skid resistant.

Recommendations for Floor Safety

1. Keep floors clean and dry. Wipe up any spilled or tracked-in liquids immediately.

2. Use a floor polish that has been tested for skid-resistant characteristics under both dry and wet conditions.

3. Avoid the use of different types of polishes having different $\mu^{\prime} s$ on the same floor or if practicable on adjacent floors.

4. Block off floor area that is being cleaned or polished and allow the floor to dry thoroughly before opening it to traffic.

5. Place floor mats at entrances to prevent tracking water into the building during wet weather.

D-9 Day, S. S., Tuten, F., Trogdon, J. and Bowen, H. "Measurement of the Skid Resistance of Resilient Smooth Floor Surfaces." Journal of Home Economics, Vol. 56, No. 10, Dec. 1964.

Describes work conducted at University of North Carolina at Greensboro, see reference $D-6$.

D-10 Esmay, M. L., and Segerlind, L. J., "Analysis of Frictional Characteristics of Stairway Tread Covering Materials," Transactions of the American Society of Agricultural Engineers, Vol. 7, No. 2, 1964. 
Have discussed the difficulty experienced in obtaining a true determination of friction coefficient between two elastic materials.

"In 1959 alone, more than 2200 farm people died as a result of falls. About one third of these accidents occurred on steps and stairways (National Safety Council, 1959). In 1959 approximately 700 farm people died as a result of falls which occurred on steps and stairways.

"The coefficient of friction was measured on a machine having a movable table under a stationary holder. ... The vertical load on the shoe soles was applied by placing weights at the end of an arm which rested on the holder. The tread materials were placed on the table and moved under the holder containing the shoe sole at a controlled uniform rate of speed. ...A vertical force of 117 1b. was used. ...The table moved at a constant speed of $14.6 \mathrm{fpm}$. ...The horizontal forces required to pull the shoe sole materials over the tread-covering materials were thus recorded on the oscillograph.

"New and worn specimens of six different tread materials and six different sole materials were used. The different sole materials were duplicated for two different sole sizes; 16.4 and $10.7 \mathrm{sq}$. in. The tread materials used were wood, linoleum, a non-skid type paint, abrasive strip, varnish and rubber mat.

"The sole materials investigated were neoprene, neolite, crepe, leather, ripple, and hard-surfaced sole made by B. F. Goodrich...

"The coefficient of friction for the abrasive strip and rubber mat materials was higher than the coefficients of friction of the other tread materials for most all of the soles investigated. Wood, varnish and paint generally showed a decrease in the coefficient of friction with use, while linoleum increased with use. The ripple sole had the highest coefficient of friction values for any of the 
sole materials studied. The crepe sole was the only sole which consistently had a higher coefficient of friction value on the new material than on the worn material."

Only averages of results were reported, with the large soles yielding values of $\mu_{d}$ from just below 0.5 for leather and B. F. Goodrich to nearly 1.0 for the ripple. The small soles yielded similar results except that the leather was about 0.3 for new sole and about 0.4 for worn sole.

D-11 "Evaluating the Slip Resistance of Floor Waxes, The Significance of Friction Measurements," ASTM Bulletin, Sept. 1958.

This is nearly a verbatim quote of Weirich's paper, D-38, which was presented at CSMA, May 1958.

D-12 Ewerdah1, S. "Halksäkerhet Hos Golvbeläggningsmateria1, "Byggmästaren, 1938, 17, 447-451, N:r 39 1938, Inneha 11. Investigations of Various Floor Materials in Relation to Slipperiness.

Although an English translation of this paper is not available, the figures and charts report the results of tests for both static and dynamic coefficient of friction of leather soles against a variety of flooring materials using a series of testing rates varying between 0 and 1.0 meters/sec. The device used was similar to the Horizontal Pull Slipmeter. Sometimes the static $\mu$ exceeds the dynamic $\mu$ and other times the reverse is true, this phenomena appearing to be affected by the test rate.

The tabulated results indicate that $\mu_{s}$ varies from 0.33 to 0.87 and $\mu_{\mathrm{d}}$ varies from 0.18 to 0.65 . 
D-13 Frederik, W. S., "Description of a New Portable Slip Testing Machine," 44th Mid-year Meeting Proceedings of the Chemical Specialties Manufacturer Association Inc., N.Y., May 1958.

Describes the design and operation of the Frederick machine. Incorporates a shoe, W2, that is twice as heavy as the surcharge, W1. Thus $\mu=\frac{W}{W 1+W 2} \tan \alpha=\frac{W 1}{3 W 1,} \tan \alpha=1 / 3 \tan \alpha$. Where $\tan \alpha$ is the tangent of the angle between the leg and the vertical. This means that to evaluate $\mu$ near 1.0 say you would have to let the articulated leg get pretty close to the floor.

Statistics: "The combined general liability experience of three large department store chains, for a period of three years, showed a total of 8,637 accidents, with 1 osses of $\$ 665,000$; 'fal1s on stairways' and 'floors' accounted for 33 percent of the accidents, 38 percent of the loss. Floor accidents, principally falls, alone were responsible for 17 percent of accidents, 20 percent of 1oss."

D-14 Gavan, F. M., Discussion of C. H. Irvine Paper, "A New S1ipmeter for Evaluating Walkway Slipperiness, "Materials Research \& Standards, Vol. 7, No. 12, December, 1967.

Questions the use of the HPS at least without a complete recognition of its precision limitations.

D-15 Gavan, F. M., \& Vanaman, J. B., "Significant Variables Affecting Results Obtained With the James Friction Machine," Materials Research \& Standards, Vol. 8, No. 11, November, 1968.

U. L. Standards, from "Accident Automotive and Burglary Protection Equipment Lists" of Sept. 1966, page 16, "Listed floor coating and 
finishing materials are of three classes: FTM, Floor Treatment Material; OGA, 0 il and Grease Absorbents; and WCM, Walkway Construction Materials. The materials 1 isted have been found to have slip resistance characteristics of not less than 0.5 as determined by the static friction test method of Underwriter's Laboratories, Inc."

Systematic investigation of the variables in the James Machine Test. Found the following variables to be particularly significant:

1. The operator (two);

2. The time under a load before the start of test (immediate or after 1 min.);

3. The rate of application of the load (the vertical load) sudden (dropped from $1 / 2$ in) or slowly;

4. The direction of the substrate (machine direction or across MD).

The three parameters that were much less significant were:

1. Speed of table (fast or slow);

2. Dry position (MD or AMD);

3. Cleaning of sensor (cotton or camel's hair brush).

Of the 64 tests run only one failed to meet the UL minimum of 0.5 .

Table 5 - Qualification of Means:

Mean Coefficient of

Static Friction

0.6991

0.6577

0.6479

0.5000
Confidence

Level (X\%)

Based on the variance of the 64 tests performed in this study. 
Conclusions "From the results obtained it is apparent that this test is greatly affected by several common variables that may be overlooked. This is likely in these days of exploding technology and transient personnel. Industrial qualifications tests should be foolproof to the testing conditions. This work is published to call attention to a situation pertinent to a rather simple test and to bolster our caution about the adoption and widespread use of such tests." There was insufficient detail in the report of the test results to permit the determination of just how the various variables considered affected the results of the James Test.

D-16 Giles, C. G.; Sabey, B. E. and Cardew, K. H. F. "Development and Performance of the Portable Skid Resistance Tester." Rubber Chem. Techno 1. 38,840 (1965).

Reprinted from "Symposium on Skid Resistance" Special Technical Publication 326, American Society for Testing and Materials (1962). Originally published by Department of Scientific and Industrial Research, Road Research Laboratory, as Road Research Technical Paper No. 66, and available from Her Majesty's Stationery Office, London.

The definitive paper on the development of the BPSRT. Gives credit to the sigler tester as the model for the BPSRT.

"The portable skid-resistance tester can carry out a wide variety of measurements. It is particularly well adapted for use on the more rough-textured surfaces. The design also makes the readings of the instrument independent of gradient, camber, or crossfall on the surface under test. 
"The instrument gives readings that correlate well with the results of tests made with patterned tires skidding at speeds of $30 \mathrm{mph}$.

The readings have also been correlated with the risk that accidents involving skidding are likely to occur on any stretch of road.

...The calibration is based on the effective weight of the pendulum arm, the distance over which the slider is in contact with the surface under test, and the nominal load on the slider. Checks made on the 150 or so machines in use show that with this kind of absolute calibration all the machines agree within an accuracy of \pm 3 percent.

"In attaining this degree of accuracy, the physical properties of the rubber used for the slides have an important role (as they do in any apparatus for studying skidding problems). A detailed specification gives the resilience and hardness properties of the slide rubber that will ensure this high standard of consistency in the readings."

D-17 Gough, V. E., "Simple Direct-Reading Friction Meter," Journal of Scientific Instruments, Vo1. 30, No. 10, October, 1953.

A complete description of the device used in D-32 and an improved version of it, which made use of relatively large discs joined together with shafts and belts.

The device is essentially a means of determining the direction of a resultant force, which when acting on a flat surface can be read off as a friction coefficient. The method of application of the normal and tangential forces is optional with the user. Unless this is well controlled one has the same problem as with other drag type friction meters. 
D-18 Gurney, S. W., "Is the floor too Slippery?" National Safety News, 1940, Aug. 22. Referred to in B-8 as discussing evaluation of slipperiness.

Gurney was Laboratory Director, Loss Prevention Department, Liberty Mutual Insurance Company.

Describes a portable version of the Hunter machine where a $3^{\prime \prime} \times 3^{\prime \prime}$ maple shoe loaded through a 10" long articulated strut is pulled across a floor until slip occurs and the angle of the $10^{\prime \prime}$ strut is recorded. This is probably measuring $\mu_{d}$ just as Hunter did.

1. Found that $\mu<0.20$ was slippery and $\mu>0.25$ was non slip.

2. Found that the more resilient the substrate the more effective $\left(>\mu_{d}\right)$ was the wax or polish on it.

3. Where there is considerable foot traffic, a freshly waxed surface is more slippery than one that has been walked on for several days, largely owing to the dust, street dirt and similar abrasive materials which are tracked onto the surface.

D-19 Hartley, Owen, "How to Use a Floor Slip Tester," The Executive Housekeeper Vol. 15, No. 11, Dec. 1968.

Suggests the use of some slip tester in public buildings to demonstrate concern in the event of law suits.

In Memorial General Hospital, Las Cruces, N. M., they use a 10\# bag and a fish scale, with a pull chain and a drop chain to be certain that their pull is horizontal at all times. They routinely check 12 places throughout the hospital, each time they freshly wax and any time they are told an area is slippery. They have found that worn terrazzo can be as slippery as tiles and thus should be waxed. "Ludox" is an ingredient in many floor polishes which causes little 
bubbles to form on the floor, thus making it slip resistant. Traffic breaks these bubbles down and reduces the slip resistance.

D-20 Hunter, R. B., "A Method of Measuring Frictional Coefficients of Walkway Materials" Journal of Research, NBS, Vol. 5, p. 329 (Aug. 1930), RP204.

Describes the Hunter Machine. The Hunter Machine is similar to the James machine in that a $3^{\prime \prime} \times 3^{\prime \prime}$ shoe is loaded vertically with $80 \#$ through a 10" long articulated strut; the angle of which is increased and monitored until slip occurs. The Hunter machine differs from the James in that the shoe is dragged across the walkway specimen until slip occurs; thus, since the shoe is already sliding when uncontrolled slip occurs, the value measured is likely to be $\mu_{d}$ rather than $\mu_{s}$. Hunter found that variations in pressure, $8.3-16.7$ \#/in ${ }^{2}$, had very little effect but that "polishing" in repeated tests reduced $\mu$. Increasing humidity decreased $\mu$ between leather and leather but usually increased $\mu$ between leather and walkway surfaces. He found that leather is a fairly consistent material. $\mu$ increases for leather on wet and/or oily surfaces. Hunter believes this is caused by a vacuum formed between the leather and the walkway surface. Hunter attempted to eliminate the vacuum by 1 ifting and dropping the shoe to simulate what he believed to occur in walking on wet or oily surfaces.

D-21 "Instructions for Using the Portable Skid-Resistance Tester," Road Research, Road Note No. 27, Department of Scientific and Industrial Research, Road Research Laboratory, London: Her Majesty's Stationery Office: 1960 .

D-22 Irvine, C. H. "A New Slipmeter for Evaluating Walkway Slipperiness," Materials Research and Standards, MTRSA, Vol. 7, No. 12, Dec. 1967 pp. 535-541. 
Compares the Horizontal Pull Slipmeter (HPS) with the Frederik Tester (FSTM). HPS uses 3.93 "/min and $10.5 \mathrm{psi}$. with the Contact sensor sanded with $6 / 0$ grit finishing paper before each series of tests.

It was found that HPS and FSTM gave essentially the same results but there are problems of consistency between operators and between different days for the same operator. Used as floor surfaces; teflon, vinyl asbestos, rubber, linoleum, vinyl plastic and asphalt.

Tefion results in $\mu \simeq 0.2$ others result in $\mu \simeq 0.5-0.6$.

Also found that stainless steel is not a suitable material to use as a replacement for leather as a test sole or sensor for the HPS.

D-23 Irvine, Charles H., "Shoe Sole Slipperiness on Structural Steel," ASTM Materials Research and Standards, Vol. 10, No. 4 Apri1 1970.

Refers to Accident Facts, ACFAA, National Safety Council, Chicago, I11., 1968.

Discussion: Sole leather, when dry, becomes hard and slippery; when wet, it turns softer and tends to adhere to surfaces. On unpainted steel, $\mu$ dry $\simeq 0.98, \mu$ wet $\simeq 0.72$. Other material such as GRS, Neoprene (foamed), Hypalon (solid) also showed increased slip resistance against bare steel when wet. Foamed hypalon, PVC (solid), rippled neoprene (solid or foamed) and solid neoprene showed decreased slip resistance when wet. The rippled design did not help slip resistance. Foamed neoprene, foamed G.R.S. \& Solid Hypalon showed increased slip resistance on painted steel but water affected it adversely for the GRS \& hypalon. Cold structural steel, $\sim 27^{\circ} \mathrm{F}$ in $78^{\circ} \mathrm{F}$ room, thus frosty, had reduced slip resistance for the materials tested, solid neoprene, solid hypalon, foamed neoprene, foamed G.R.S. 
D-24 James, Sydney V., "What Is a Safe F.loor Finish?" Soap and Sanitary Chemicals, Oct. 1944.

This appears to be the only article published by , Sydney $V$. James.

It presents a general discussion of the interest of U.L. in floor slip-resistance and the biomechanics or kinesiology of human locomotion. He concludes "The essential point of this process, it seems to us, is that the shoe is in stationary contact with the floor during the walking action. There may be some difference of opinion as to this. It would be extremely interesting to see 'slow-motion' moving pictures of the walking process. I think we should see clearly that the shoe, although it may rock or roll slightly during the step, is essentialiy in stationary contact with the floor. If a person tries to take too long a step on a slippery floor, the leading foot may slip because, in attempting to transfer the weight to it, the angle of the leg is too great and the friction at the shoe contact will not keep the foot from slipping. Similarly letting the leg take too great an angle backward may also result in slipping. Think of a person walking on stilts. On a slippery floor short steps are necessary, while on a rough floor long strides become possible.

"Another point which should be considered is that the friction between two bodies in stationary contact is greater than if the bodies slide relative to each other. We believe that it is necessary to take this into account when analyzing the walking process."

James then developed a test method for floor slip-resistance by considering and rejecting previous methods such as: the variably inclined plane since the normal force varies; a dragged shoe since this is generally dynamic friction; a propelled shoe, measuring the stopping distance, which is again dynamic and a non-constant velocity; 
and the pendulum which is again dynamic and a non-constant contact pressure or velocity. He then describes his machine which was based on the Hunter machine, as to $3^{\prime \prime} \times 3^{\prime \prime}$ shoe and 75\# force, resulting in $81 / 3$ psi, which is less than that for a man but he claimed that for pressures above 6 psi the $\mu$ was not affected by pressure. His description of his device would indicate that it was intended for testing in-place floors as well as flooring materials, yet the devices bearing his name are only suitable for testing samples of materials.

"Summing up the matter, therefore, our method of answering the question 'what is a safe floor finish?' is to compare the surface friction of the finish-coated floor with that of the untreated floor and then if the coefficient of friction of the treated or finished surface is no less than that of the untreated surface, the finish is regarded as being a safe finish. This is a relative or comparative method. It is based on the assumption, amply justified by experience, that the various forms of commonly used floors and floor coverings are safe enough for use without any finish material being applied."

D-25 Johnson, Bayard S., "A Discussion of Some Factors Influencing Slip Resistance Measurements," CSMA, Proceedings of the 44th Midyear Conference, May 1958.

Refers to NBS slipmeter tests. He assumed a shoe contact area of 15 in. $^{2}$ and thus postulated contact pressures of 10 psi from 0.1 second after impact to 0.6 second after impact and then falling rapidly to zero. James and HPS approximate this. He further postulated that in the first part of a step, on a new sharp edged heel the pressure on 0.2 in. $^{2}$ could be as much as 375 psi. He mentioned "A 1 imited number of tests on certain types of floor wax formulations shows that the static coefficient of friction decreases under high pressure, probably due to plastic flow of the wax composition." Then suggests the $\mu$ needed for normal walking is not high, possibly 
not greater than 0.2. Then discusses the need for higher values of $\mu$ and possibly a relatively high ratio of $\mu_{d} / \mu_{s}$ to control stumbles, losses of balance, slips etc.

Then discusses an evaluation of the Sigler machine on bond paper over a sheet of carbon paper. With a hard heel against a hard substrate, asphalt tile, the carbon paper revealed a nonuniform contact pressure trace. For the same heel on a soft substrate, rubber, the trace was much more uniform, also for soft leather shoes. This throws doubt on the sigler values.

D-26 Kellett, P. H. "Modern Solings in Wear," SATRA Information Publication I. P. 16, SATRA Symposium on Injection Moulding, June 28, 1968.

Describes the ramp test, angles $>15^{\circ}$ are preferred but sole or floor surface is not considered dangerously slippery unless the slip angle is below $10^{\circ}$. Measurements are made both wet and dry.

Ramp appears to be about $12^{\prime}$ long and the upper end is elevated by means of a rope hoist.

Gives some slip results for rubber \& PVC, against clay and vinyl tiles, wet and dry.

1. Rubber is generally less slippery than PVC.

2. Both rubber and PVC are dangerously slippery on wet surfaces when their hardness is less than 55 IRHD.

3. PVC's of 80 IRHD or over are very slippery on wet and dry surfaces.

IRHD is a measure of hardness of PVC or rubber, etc. Polyurethane was found to behave much as rubber as to slip and wear. Thermophastic SBR soling has excellent skid resistance. Ethylene Copolymers have satisfactory skid $\underset{56}{\mathrm{rasistance}}$ 
Tests of top pieces (heel taps for women's heels)

\section{Slip resistance}

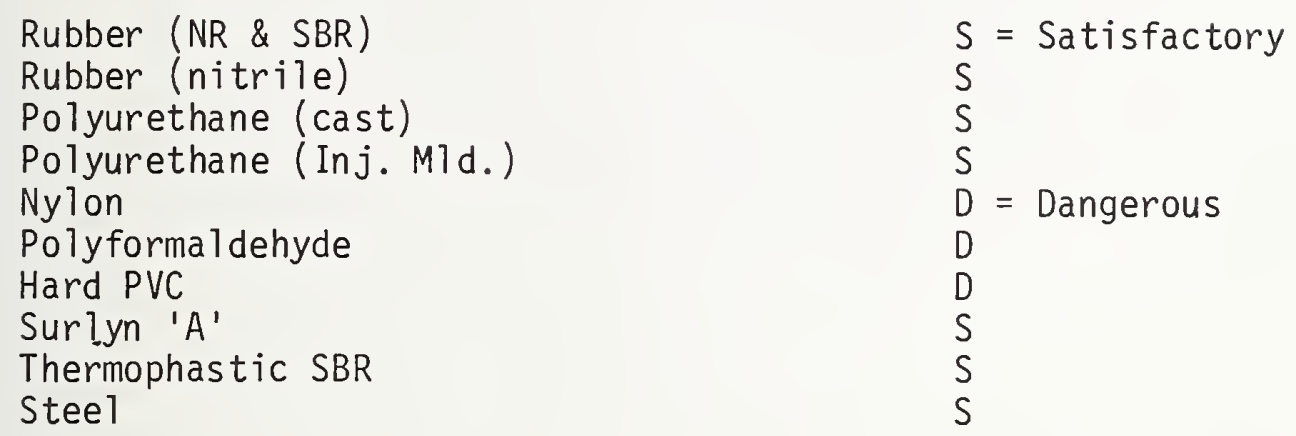

D-27 "Measurement of the S1 ipperiness of Walkway Surfaces," Rubber Age, Vo1. 62, Dec. 1947, pp. 296-297. No author, but it appears to have been written by Percy Sigler.

Describes efforts of National Safety Council to collect data regarding accidents to make a statistical study and efforts of NBS to measure slipperiness. Questioned earlier devices on grounds that they were concerned with starting rather than sliding friction and an appreciable area of contact between sole and floor surface was generally used. Thus more representative of a person standing than of someone in the process of walking, when most slips and falls occur.

This is where the delay between application of vertical load and tangential load becomes vital. Discusses concealed camera observations of walkers and study of worn heels and development of the Sigler Tester. Does not claim that the "antislip coefficient" is a coefficient of friction. 
Describes in general terms some tests of concrete blocks, ground with carborumdum and worn from 25 years of service; rubber tile with and without alundum grit; a rubber matting with cotton fibers; floors at Walter Reed and the Pentagon. Some general conclusions but very little specific data.

D-28 "Model 80 Floor Friction Tester," Promotional Literature, Technical Products Co., 264 Park Ave., N. Caldwe11, N. J. 07006.

Describes a slip-resistance tester consisting of a $10 \#$ weight and non-linear spring balance that permits low drag forces to be measured with the same relative precision as larger forces. The sensor area is $31 / 2^{\prime \prime} \phi$ leather buttons disposed much the same as on the Horizontal Pull slipmeter.

D-29 Modern Sanitation and Building Maintenance, Vol. 11, No. 7, p. 6 (1959)

Describes use of $10 \#$ bag of lead shot pulled by a fish scale, on two layers of cheese cloth;

Force less than 3\# implies slippery

Force greater than $5 \#$ implies safe

Research Department of the Hospital Bureau Inc.

D-30 "Progress Report to the National Safety Council Committee on Safe Walkway Surfaces," Oct. 1, 1949 - Mar. 31, 1950.

Reports a large number of tests of floors with what is presumed to be the Sigler Tester. Generally a rubber heel is less slippery than leather and dry is less slippery than wet, for both rubber and leather. Wet leather can go as low as $\mu=0.14$ on floors maintained 
with solvent type wax, and dry leather can go as low as $\mu=0.24$ on the same floors. Wet rubber can go as low as $\mu=0.15$ on the same floors while dry rubber has a low $\mu$ of 0.47 on the same floors.

The highest $\mu$ in any case is $\mu=0.95$ for dry rubber on a linoleum corridor scrubbed, cleaned, waxed and not polished, with silica. Force plate tests of 7 men and 5 women revealed that the maximum required value of $\mu$ was $\mu=0.2$ on the heel and $\mu=0.5$ on the toe except for one 140\# man, 5'8", 27 years old who developed $\mu=0.75$ on the toe just at the end of his stride.

This is essentially the same as reference B-5 except that this has more data.

D-31 "Proposed Method of Test for Measuring the Static Coefficient of Friction of Waxed Floor Surfaces," and "Proposed Method of Test for Measuring the Dynamic Coefficient of Friction of Waxed Floor Surfaces," ASTM Bulletin, No. 196, Feb. 1954.

The first was adopted as ASTM D2047-72, The James Test. The second describes the Sigler Tester and was apparently never adopted.

D-32 Robinson, W. H. and Kopf, R. E., "Evaluation of the Horizontal Pull Slipmeter, "Materials Research and Standards, Vol. 9, No. 7 American Society for Testing and Materials, July 1969.

Points up the need for a device to measure the static $\mu$ of actual in-use floors. Paper deals only with the static $\mu$ 's. For the Horizontal Pull Slipmeter (HPS) variations of speed between 2, 3.93 and $5 \mathrm{H} / \mathrm{min}$. had little effect on the test results. 
The Instron machine demonstrated that the HPS gives reliable static results. The Instron was used to pull the HPS and both the Instron and the HPS loads were read. The James Machine gave consistently higher results than the HPS. For ten repeated HPS tests, $S$ varied between 0.012 and 0.056 . For 4 repeated James tests $S$ varied between 0.015 and 0.060 , where $S$ is the standard cieviation.

D-33 Schjödt, R. "Measurements of Human Reaction to Hardness of Floor Covering," ASTM Bulletin No. 247, July, 1960.

Mostly recorded normal forces, but a bit on coefficient of friction measured by pulling a weighted sole along the floor as described or specified in G-8. "In some cases special test floors could be tilted so that the friction angle could also be measured directly."

Last two tests were included to check why, in the lobby of a research institute it was found necessary to put up warnings. Fine sand appeared to lubricate the limestone but not terrazzo.

Author claims that the results show that the kinetic $\mu$ ought to be not less than 0.20 and not more than 0.4 for leather soles. In some cases, dry on rubber and sheet vinyl, kinetic $\mu$ for rubber is greater than the static $\mu$. 


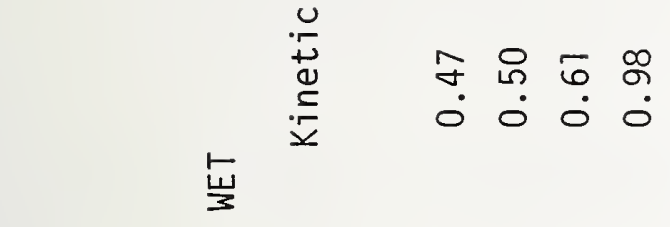

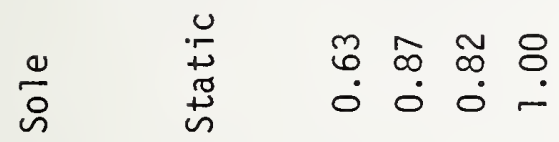

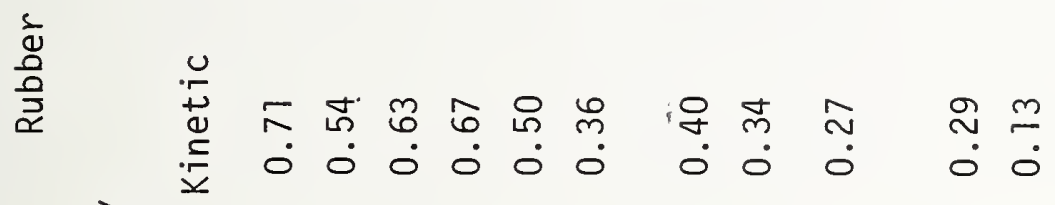

$$
\begin{aligned}
& \text { 产 }
\end{aligned}
$$

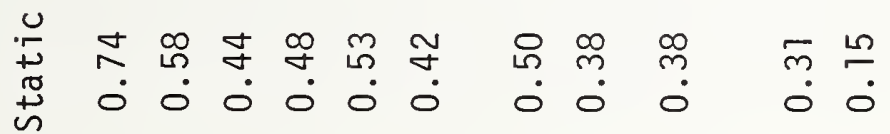

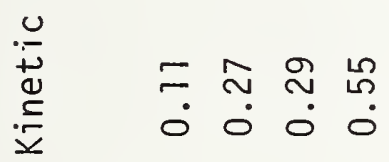

$$
\begin{aligned}
& \text { 荘 }
\end{aligned}
$$

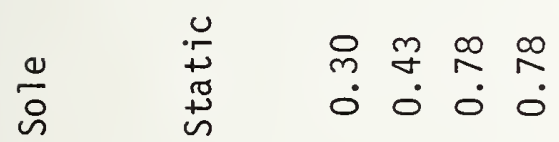

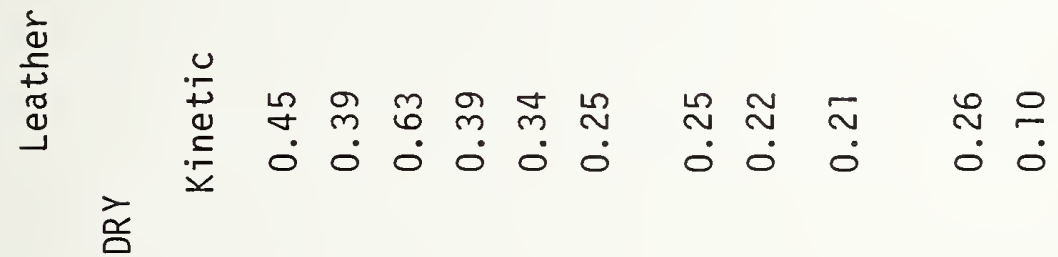

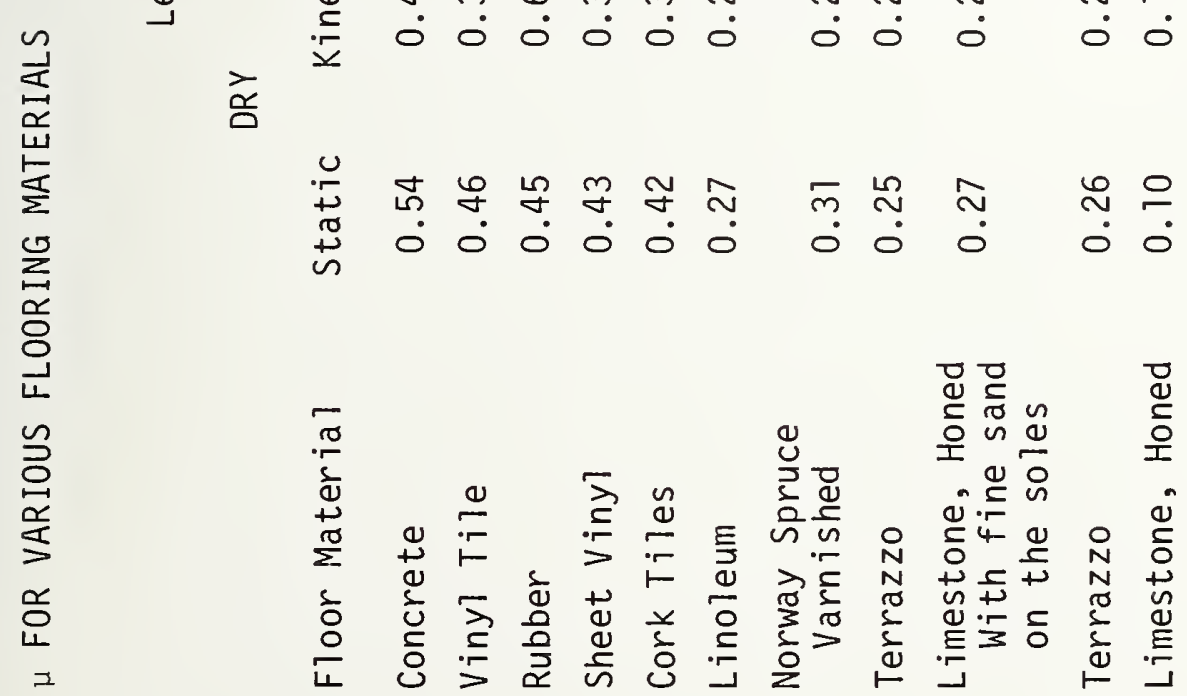


D-34 Sigler, P. A. "Relative Slipperiness of Floor and Deck Surfaces." U. S. National Bureau of Standards, Building Materials and Structures Report, B.M.S. 100.

Recommends the Sigler test for dry and wet floors, dirty, clean soapy, even oily.

Most materials satisfactory when dry but dangerous when wet.

Was concerned by the previous findings that $\mu$ static for wet surfaces was frequently higher than for dry surfaces. Thought that this was because the Hunter or James machine made just too large an area in contact, one more representative of standing, than walking. Max. vel. of heel at strike $\simeq 500 \mathrm{ft}$. $/ \mathrm{min}$.

Avoids reference to a dynamic coefficient of friction, but merely calls it "antislip coefficient."

Tested in an environment of $\mathrm{T}=72^{\circ} \mathrm{F} \quad \mathrm{RH}=65 \%$

$$
\begin{aligned}
\text { clean }= & \text { exceptionally clean floor } \\
\text { dirty }= & \text { china clay sprinkled on the floor = very dirty } \\
\text { soapy }= & 0.5 \% \text { solution }=\text { a maintenance procedure using } \\
& \text { a very strong soap solution and no rinsing. }
\end{aligned}
$$

Wear of stone floors was simulated by grinding with 180 grit. excessive oil yields $10 \mathrm{w} \mu$; excessive $0 i 1$ wiped away yields same $\mu$ as wet.; oily $\mu$ increased slightly by sprinkling china clay. 
A wealth of data, no mention of number of replications

Suggested limits

Antislip value

(classification)

poor

fair

good
Leather heel

(antislip coefficient)

$<0.15$

$0.15-0.30$

$>0.30$
Rubber heel

(antislip coefficient)

$<0.25$

$0.25-0.40$

$>0.40$

Rubber heels are more likely to create surprises on wet surfaces. Leather heels are more likely to slip on dry wax.

D-35 Sigler, P. A., Geib, M. N, Boone, T. H. "Measurement of the Slipperiness of Walkway Surfaces." J. Res. National Bureau of Standards, 1948, 40, 339. Also Research Paper RP 1879, May 1948.

"Slow motion pictures of people walking were taken with concealed cameras so that the subjects were unaware of being photographed and were thus likely to be walking naturally. These pictures reveal that the leg slows down at the termination of its swing and then appears to vault onto the walkway, the other leg being used as a pole. They also show that the foot is first placed upon the walkway so that only the rear edge of the heel contacts the walkway surface during the early stages of the retarding phase of a step. The other foot remains in contact with the walkway, thus bearing part of the vertical load, until the heel rocks forward and the foot is fully planted. Then follows a survey of worn heels and motion pictures which shows that probable angles that heels make with a walkway surface at the first instant of contact vary from $11^{\circ}-33^{\circ}$ with an average of $19^{\circ}-26^{\circ}$. 
"According to the literature (Elftman B-6) the horizontal component of the force exerted by the leg on a walkway surface reaches a maximum in the forward direction shortly after the heel makes contact with the walkway, decreases rapidly at first and then slowly as the foot deploys, and rapidly reaches a maximum in the backward direction as the ball of the foot prepares to leave the walkway. These horizontal components are the forces that must be counteracted by friction in order to avoid slipping." Then a justification of the need for a portable device. Then a description of the design and use of the Sigler machine.

Here the claim is made that the max. linear velocity of the heel from a release ht. of $10^{\prime \prime}$ is $150 \mathrm{ft} . / \mathrm{min}$.

"In genera1, lower antislip coefficients were obtained with increase in the pressure." "Therefore, the antislip coefficients obtained by this method should be considered as relative rather than absolute values and the establishment of a minimum antislip coefficient for walkway surfaces as a specification or code requirement would have to be based on a definite method of test."

The results of this test, considered in relation to slip-resistance as actually experienced, indicate that a slippery condition does or does not exist, according to whether the measured coefficient is less or greater than 0.4 .

A large number of test results... "A11 the walkway surfaces gave relatively high antislip coefficients with dry rubber heels, and thus good traction should be experienced with such footwear. In genera 1, much lower coefficients were obtained with dry leather heels, the values ranging from one indicating poor traction, 0.30 , to one indicating good traction, 0.50." 
D-36 "Standard Method of Test for Measuring Surface Frictional Properties Using the British Portable Tester," ASTM Designation E303-69.

D-37 "Tentative Test Method for Qualitative Determination of Slip Resistance of Floor Polishes," CSMA Committee "N" CSMA Bulletin No. 11768, May 7, 1968.

Describes the shoe on paper, subjective test of floor slip-resistance.

This was later revised in Ju1y 22, 1970, to become CSMA-Bulletin No. 245-70; CSMA Tentative Method, Comparative Determination S1ip Resistance of Floor Polishes. See F-4.

D-38 Weirich, C. L., "Static Coefficient of Friction, Significance of Test Results," Clarence L. Weirich, presented before the CSMA, May, 1958.

Found that variation in the weight bearing down on the shoe does not affect the readings (within experimental range).

For steel on steel the above is generally true.

For a leather shoe on bare asphalt tile for top wts. from 19.3131.0\# and shoe sizes of 0.5 in. $^{2}, 1 \mathrm{in}^{2}, 4 \mathrm{in}^{2}$ and $9 \mathrm{in}^{2}$ the results were very consistent. For wts. of $17.3 \& 19.3 \#$, $\mu$ was too high, probably caused by excessive friction in the machine.

For a leather shoe on waxed asphalt tile or on waxed TOTAT, fairly consistent results were obtained for areas 4 and 9 in. ${ }^{2}$ and all top wts. There was some indication of high readings for low top weights. But for the small areas, 0.5 and $1.0 \mathrm{in}^{2}$ the results were much 
lower, as much as 1/3 lower, indicating that at these high contact pressures something is happening to the wax-leather interface to make it less slip resistant.

A general discussion of "Evaluating the Slip Resistance of Floor Waxes." Generally reservations on the usefulness of available machines in other than laboratory conditions. Reference to other causes of slips; trash on floors such as flower debris in hospital rooms, the tendency of people to change gait when stepping onto a shiny floor, etc.

D-39 Williams, W. D., Smith, J. A. and Draugelis, F. J. "TOPAKA, A New Device and Method for Measuring Slip Resistance of Polished Floors," Soap/Cosmetics/Chemical Specialties, July, 1972.

Claims that results of James machine do not correlate with foot traffic experience in all cases. "We have had manufacturers of polish tell us that their slipperiest polish gets the highest James Machine Coefficient of friction."

Found good correlation with shot bag but too many uncontrolled variables. CSMA test Method and Foot Evaluation,- CSMA uses a panel of observers, using a piece of clean paper under the shoe. 5 \# total wt. with shot bag on $81 / 2^{\prime \prime} \times 51 / 2$ " paper, $25 \%$ rag content bond "Weston Bond Fluorescent." Shot bag $\sim 5 "$ " 8 " Thus pressure $\simeq$ $1 / 8$ psi. Windlass similar to Horizontal Pull Slipmeter except 110 volts, 3.3"/second, nylon cord.

Small portable sling psychrometer is routinely used.

Chatillon DPP5 push-pull spring scale with maximum load button. For higher contact pressures used three $1 / 2^{\prime \prime} \phi$ gum rubber buttons, $A=0.59$ in. $^{2}$ thus pressure $\simeq 8.5$ psi. compared with $15 \mathrm{psi} \simeq$ average man's walking pressure. 
On polymer products found pressure to have no effect, not as confident on al1-wax products.

Found that the cheesecloth seemed to dig into all-wax products and give results higher than actual foot feel would indicate. Paper seerns to give better correlation.

Tested 15 products with values of dynamic $\mu$ varying from 0.300 to 0.158 . Of the 15 materials only one had a statistically significant number of tests, 147; the others had from 2-4 tests. For the one with 147 tests $\mu$ varied from 0.21-0.44. They concluded that $\mu$ $>0.24$ implies slip resistant, $0.2 \leq \mu \leq 0.24$ implies acceptable slip resistance, $\mu<0.2$ implies marginal slip resistance.

\section{Findings:}

1. The same polish acts differently on different types of flooring.

2. The number of coats of polish influences the degree of slip resistance.

3. Temperature, within reasonable limits, is not very important.

4. Humidity is important: generally, higher relative humidity will increase slip resistance.

5. Recoatability of polish is important; film disturbance, crazing, can influence slip resistance.

6. Age of the polish film; as polish hardens with age and traffic, slip resistance can change.

7. The last treatment of the floor is important; e.g. just spray-buffed (and with what), just washed, buffed, etc.

8. The particular area of the floor where slip resistance is measured is important too. High traffic areas versus those with low traffic.

D-40 Wilson, Angus, and Mahoney, Patrick, "Measuring Frictional Properties of Soles and Heels," Rubber World, March 1972. 
Describes an inclined-horizontal test track and carriage designed at the U.S. Army Natick Laboratories to study dynamic friction between rubber soles and heels and typical floor surfaces. "In evaluating sole and heel materials, we are concerned with the retention of traction, or the prevention of skidding, and so sliding friction is of interest. Loading, based on heel contact point measurements, is calculated to be $88 \mathrm{psi}$. for a $150 \#$ man; speed is taken as the 2.5 to $4 \mathrm{mph}$ generally considered to be that of walking. ... The test specimen may be 1 " or $3^{\prime \prime}$ wide and is flanged to fit into a slotted holder angled at $15^{\circ}$ to the horizontal. The $1 "$ specimen has a contact area of approximately $0.18 \mathrm{sq}$. in. A specimen loading of 16 lbs. or approximately $88 \mathrm{psi}$ is achieved with a carriage weight of $30 \#$.

"The carriage skid distance, measured from specimen contact point, is used as a comparative measure of friction. In cases of very low friction, on wet tile for example, the average speed over the last foot of horizontal track is measured using a micro switch and millisecond timer." Found that a layer of floor dust, natural or artificial, consisting of whiting, talc, clay and carbon black, increased skid markedly on tiles but only slightly on concrete; making concrete the most skid resistant--which seems to agree with more subjective evaluations.

Comparison with Portable Skid Resistance Tester (presumed to be the British PSRT) resulted in the relationship:

Carriage skid $=\frac{1380}{\text { Port Skid Resist. Units }}$ within $\pm 2 \%$

"Both apparatus show that clean smooth surfaces have comparatively higher frictions and that wet or dry lubricating layers on such surfaces drastically lower it. This can be explained by that component of friction commonly designated as adhesion, attributed 
to the attractive forces between the rubber and contacting surface. on rough surfaces, like concrete, contact is poorer and the component designated as deformation takes precedence, with the interfering layer having less effect. ... In general, the results obtained from the various tests show that it is extremely hazardous to try to predict the frictional characteristics of a heel or sole compound from other physical properties, or from the type of rubber used." They must be tested specifically for friction. 
E-1 "Causes and Measurement of Walkway Slipperiness," Federal Construction Council Technical Report \#43, National Academy of Sciences National Research Council Publication 899, Washington, D. C. 20418

A good basic report but somewhat out of date, 1961.

Objective to recommend performance tests, safety from slippage only, primarily interior surfaces.

1. The causes of slipping

2. Methods of determining relative slip resistance

3. Need for standardized means of expressing degrees of slipresistance

4. Need for methods of measuring slip-resistance

A task group from six federal agencies

Conclusions

Existing test methods are good laboratory tests but are highly subject to variable environmental conditions. Couldn't at that time set standards, either a value or a method of measurement.

Suggested the establishment of standard surfaces and some simple device for comparing field surfaces with the standards. Return the standard surfaces for recalibration from time to time. 
Recommended Research Topics:

1. Establish standard surfaces

2. Develop a portable device for slip measurement

3. Conduct an extensive series of field tests

4. Determine a standard

Then classify and recommend materials and maintenance techniques on the basis of their slip-resistance.

Discussion

Brief discussion of mechanics of walking

Factors influencing frictional requirements and floor safety

Floor Factors:

Layout and variety of floor finishes

Location of Surface

Physical shape of surface

Pedestrian Factors

Individual considerations

Psychological considerations

Amount of Traffic

Speed of Traffic

Type of Personnel

Footwear Factors:

Area of contact

Composition of heel and sole materials

Proper fit of the shoe

Then a discussion of the Fundamentals of Friction and methods for measuring it including rolling and stopping friction 
Discussion of Machines for Measuring Friction

Horizontal Track, including the Hunter, James and an instrumented polisher

Inclined track or plane

Pendulum machines, Sigler and BPST, also wheels and a puck impeller Evaluation with the foot

Problems with testers

1. Which type of friction, static, kinetic or stopping controls the slip of a foot?

2. Operator induced variables and variations in the conditions of the machine

3. Elastic properties of the sliding materials

4. Geometry of the surface

5. Boundary film and matter prevailing at the surfaces of contact.

A table comparing 11 methods of measuring floor slip-resistance is included.

E-2 Chaffin, Don B. Private Correspondence from visiting professor, Department of Industrial and Systems Engineering, College of Engineering, University of Florida, Gainesville, Fla. 32611.

He suggests that "too much friction may be harmful to the musculoskeletal system" and that "the floor/foot interface is only one component which may influence the hazard potential of a given man-task-environment system. Before seeking further opinions, I would suggest a more open debate of experts to define the broader system characteristics, so that any resulting measurement schemes are realistically defined to meet valid and logical safety health criteria." 
E-3 Cramp, A. P. and Masters, L. W.; "Preliminary Study of the Slipperiness of Flooring," National Bureau of Standards Report, NBSIR 74-613.

E-4 Gutt, W. Private correspondence from Department of the Environment, Building Research Establishment, Building Research Station, Garston, Watford, WD2 7JR.

He indicates that static friction measurements are usually favored although the possible influence of dynamic friction, particularly in turning maneuvers, is recognized. From their studies of the $V$ and $H$ forces they have concluded that a value of $\mu_{s} \underline{J} 0.4$ is desirable. They have observed that lack of slip-resistance leads to falls most often when there is heel only contact even though that does not usually result in the maximum value of $H / V$. "Although classical theories of friction are based on the concept that the coefficient is independent of load this may not be true of floorings that are easily compressible. If one is measuring static friction, I see no reason for simulation of normal walking behavior but in situations where dynamic friction could be more important then other considerations such as angular velocity need to be considered." They use three contact materials: steel, leather and rubber. "The results often indicate that with some materials the floor is safe but with others it may produce a chance of slipping." He comments on the effects of contaminants such as water, wax, grease, etc., particularly water. "A fruitful source of investigation seems to be an examination of the behavior of water films on the flooring under different loading conditions and how moisture might be transferred to the floor surface from contact with damp (not wet) footwear."

E-5 Heath, Arthur L. Private correspondence with Associate Director, Myodynamics Laboratory, The University of Rochester, School of Medicine and Dentistry and Strong Memorial Hospital, 260 Crittenden Boulevard, Rochester, N.Y. 14620. 
His letter gives a good discussion of the variation of force and pressure under the foot when walking, referring to two of his published papers; C-23, C-24.

E-6 Hopkins, S. K. "Elusive Factor in Falls: the Shoe Sole," National Safety News, NSANA, Nov. 1966, pp. 34-39.

Referenced in D-23 and quoted "The reason for this neglect (safe shoes) is lack of information. Almost no valid research relating to slip resistance of shoe soles and heels has been published. Recommendations of shoe and shoe sole makers are at best very genera 1 , often vague, and sometimes conflicting. There is no generally accepted method of measuring the slip resistance of shoe soles or heels on various surfaces."

Followed in the same journal by "How an Antislip Sole was Born." French Testing and design research led to a tread unlike anything in the U.S.

This describes a tester which subjected a pair of shoes to a normal force of 45-350\# in 45\# increments and applied a gradually increasing lateral force until slip occurred. The average $\mu$ for each direction of pull on a given surface was determined by averaging the $\mu^{\prime} s$ obtained with different loadings.

E-7 Jablonsky, R. D., Private correspondence from Truesdail Laboratories, Inc., Chemists, Microbiologists, Engineers, 4101 N. Figueroa Street, Los Angeles, Cal. 90065.

He believes that friction between the shoe and the floor is only one of many factors that relate to slipping and falling. He feels that efforts to invent yet another new instrument for measuring floor friction are not justified by the present state of the floor 
slipperiness art. He implies that Truesdail uses the Sigler machine with a value of $\mu_{d} \geq 0.3$ indicating that the floor is not a significant contributor to slips and falls. He supports the use of ASTM, D2047 with an attempt to correlate the results with actual falls. This, of course, is hard to do since D2047 is not suitable for field use. He recommends the use of the sigler test as a field test until some device is developed that is suitable for both laboratory and field use. Believes that it is important to standardize on a field test method as quickly as possible so that all interested parties will be using the same test method. He suggests interim measures such as a high safety factor on required $\mu_{s}$ until more is learned in a scientific way. He cites the successful use of the British Portable Skid Tester for evaluating pavements as a demonstration of the value of a sigler type machine. Finally he notes that from their many investigations of slip and fall accidents a large percentage occurred under circumstances other than normal walking.

Thus it may we11 be necessary to evaluate a variety of stride patterns and other maneuvers. He also listed such other factors in the slip and fall equation as: condition and types of shoes and materials; size, shape and stride of the individual; surrounding environmental conditions; and the physiological and psychological conditions of the individual at the time of the fall.

E-8 "Keeping Employees on their Feet," National Safety News, Sept. 1970.

Discusses safety of various types of shoe soles and shoe sole materials including the squeegee shoe developed in France. Quotes the significant results from $D-23$. 
E-9 Rodstein, Manuel, MD, Accidents Among the Aged," 1963, National Safety Counci1, 425 N. Michigan Avenue, Chicago, I11. $606114 p p$.

Falls of persons occur more frequently and have more serious results, on the whole, than any other type of accident in commercial establishments. Then quotes the accident statistics from D-13. Falls of persons on floors is an especially acute accident problem in stores, hotels, restaurants, and theaters, because their clientele frequently includes a large percentage of older persons, and these older persons are usually more susceptible to serious injury from this type of accident than are younger people.

E-10 Waters, E. H.; "Some Special Problems of Floor Design From the Safety Aspect," Report No. L10, Division of Building Research Commonwealth Scientific and Industrial Research Organization, Commonwealth of Australia, Melbourne, 1960.

A general description of floor hazards, including insufficient slip-resistance and some general guidelines of what to do. No mention of any quantitative way to evaluate slip-resistance.

E-11 Wilson, Angus F., Private Correspondence from Chief, Polymer Applications Group; Polymers and Organic Materials Br.; Materials Applications Division; Clothing, Equipment and Materials Engineering Laboratory, U. S. Army Natick Laboratories, Natick, Mass.

Suggests that both static and dynamic friction should be measured, under the range of loads likely to be encountered in real situations. Believes that testing must be a compromise between the practical desire for a simple, reproducible test procedure and the need for reproducing actual field conditions with all the variables that are likely to be introduced. "As an example, our previous testing showed that with compounds of 9 different base rubbers the 
dynamic friction was higher on clean floor tiling then on concrete. Our experience tells us this is not true. The addition of a layer of dust to the tiles reverses the situation so that it is in accord with our experience and more representative of reality. In my opinion this aspect has not been properly taken into account in most of the work that has been done on evaluation of floor slip properties. The effect of water is often evaluated but this is only one material found on floors. Selection of others, or mixtures of others, as representative of real situations is extremely difficult, but I feel that it should be considered." 
F-1 Chemical Specialties Manufacturers Association, "CSMA Procedure for Products Classified as to S1 ip Resistance" CSMA Bulletin \#308-70, December 8, 1928.

Adopts the value of $\mu \geq 0.5$ as the criteria to determine if a product should be classified as slip resistant, anti-slip, or terms of similar import. Implies the use of the James machine to determine $\mu$. Thus $\mu=$ the static coefficient of friction.

F-2 CSMA Bulletin No. 245-70, July 22, 1970, Waxes, Polishes and Floor Finishes Division

Exact same wording as F-24. Documents the passage of the tentative Standard CSMA Test Method by the Wax Scientific Committee, the Wax Executive Board, and the Board of Governors of CSMA at the 56th mid-year meeting in May, 1970.

F-3 CSMA Bulletin No. 308-70, December 8, 1970. CSMA Procedure for Products Classified as to STip Resistant, signed by John D. Conner, General Counsel \& W. S. Jessop, Chairman Standards and Specifications Appraisal Committee. Reports the adoption of the resolution on F24 by CSMA Board of Directors.

Quotes Rule 5 of the Proposed Trade Practice Rules for the Floor Wax and Floor Polish Industry, published March 17, 1953.

This includes both the James Machine test with $\mu_{s} \geq 0.5$ and the Sigler Test with $\mu_{d} \geq 0.4$; actually the Sigler Test is referenced first. 
Then refers to section 5 of the FTC Act which prohibits any unfair trade practice and points out that FTC never promulgated the proposed rules in final form because the legal significance to have done so would be to make the rules evidence in a proceeding for violation of Section 5 of FTCA of the practices which the industry considered to be unfair. Although the proposed rules were not promulgated in final form, they have been considered by the industry as broad guidelines of acceptable practices.

Then claims that U.L. and CSMA certification procedures are the same except that U.L. demands that a 11 tests be performed in their laboratory and specifies the frequency. "If a member of the industry wishes to make a claim that his product meets the CSMA standard, he must assume the responsibility for conducting the necessary tests to assure that the product does meet this standard. This testing may be done either in independent testing laboratories or in companyowned laboratories, or in both." "Then limits the wording of the claim a manufacturer can use and presents several examples that are currently in use.

F-4 CSMA Tentative Method, "Comparative Determination of S1ip Resistance of Floor Polishes," CSMA Bulletin No. 245-70, July 22, 1970.

Presents the revised form of that on D-37.

Approved in Chicago May, 1969.

F-5 Doering, R. D., "Defining a Safe Walking Surface," National Safety News, August 1974 .

Some good references to the legal aspects of the floor slip-resistance problem. 
A yeoman effort to force the problem into a matrix formulation, not very effective. A direct quote from D-35 on the mechanics of walking and the importance of the angle between the heel and the floor. A reference to the possibility of dictating the shoe in some cases such as for kitchen workers on wet-greasy quarry tiles. A comparison of available Friction test instruments.

Referred to Federal Test Standard 501A Method 7121 for use of Sigler Machine. Referred to D-35 "That a slipping condition does or does not exist according to whether the measured coefficient is less than or greater than $0.40 . "$

Studies time dependent degradation of surface of polyurethane matrix and crushed glass as to $\mu$ (sigler), dry and wet, with and without a sealer.

Test machines considered: Sigler, James, Frederik, Shot Bag, Topaka, Horizontal Pull Slipmeter, Foot Evaluation.

F-6 Fed. Spec. RR-G-1602, Ju1y 10, 1970, Federa1 Specification Grating, Metal, Other Than Bar Type (Floor, Except for Naval Vessels).

Specifies Antislip by including the following table. The equivalent values of coefficient of friction have been introduced by the author.

3.6 Friction when specified (see 6.2), the minimum friction for foot traffic shall be as shown in Table II. 
Table II Antislip values

Condition

Minimum Antislip Values (pounds)* steel Aluminum $\mu$

$\begin{array}{lrrrr}\text { Dry } & 110 \# & 0.76 & 105 \# & 0.73 \\ \text { Mud } & 110 \# & 0.76 & 95 \# & 0.66 \\ \text { Ice } & 80 \# & 0.55 & 75 \# & 0.52 \\ \text { Grease } & 95 \# & 0.66 & 75 \# & 0.52 \\ \text { Detergent } & 108 \# & 0.75 & 95 \# & 0.66\end{array}$

* Minimum force in pounds, acting to prevent a $1451 \mathrm{~b}$. weight from slipping.

F-7 Federal Trade Commission, Washington; "Proposed Trade Practise Rules for the Floor Wax and Floor Polish Industry." For release in morning newspapers of Tuesday, March 17, 1953.

This is the only officially published version of these rules, including Rule 5 "IMPROPER USE OF THE TERMS "SLIP RESISTANT:, 'SLIP RETARDANT, ' 'ANTI-SLIP, ' ETC."

"It is an unfair trade practise to use the terms 'slip resistant,' 'slip retardant,' 'anti-slip,' or terms of similar import, as descriptive of any industry product which does not contain slipresistant properties sufficient to assure that a floor surface to which the product is applied will be substantially safe for walking.

"Note: Subject to the development and acceptance of improved testing methods, either of the following tests with resultant coefficients of friction may be employed for the purpose of determining compliance with this rule:

"(1) A coefficient of friction of not less than 0.40 as determined by averaging the results of four separate Sigler tests of different areas of the surface. The sigler test shall be made at room temperature $\left(731 / 2^{\circ} \pm 2^{\circ} \mathrm{F}\right.$.) with relative humidity of $50 \% \pm 4 \%$. Four 
tests shall be made using a leather test piece of hard, firm, sole leather conforming to Federal Specification KK-L-26lc (leather; sole, vegetable-tanned, factory) except that the compressibility of the leather shall be restricted to $6 \% \pm 2 \%$."

(2) A coefficient of friction of not less than 0.05 as determined by the test for slip-resistance as used by the Underwriters' Laboratories, Inc., at the time of promulgation of these rules.

This rule is preceded by: Rule 4 - IMPROPER USE OF THE TERMS "SLIPPROOF," "NON-SLIP," "NON-SKID," ETC.

"In the sale, offering for sale, or distribution of any industry product it is an unfair trade practice to use the terms 'slip proof,' 'non-slip', 'non-skid,' or terms of like import, as descriptive of such product unless it will completely prevent slipping on any floor surface to which it is applied for the duration of the product thereon."

Note. It is the judgment of the industry that no industry product of present commercial manufacture is qualified to be designated as "slip proof," "non-slip," or "non-skid."

A notice of hearing and of opportunity to present views, suggestions, or objections to these proposed rules appeared on page 1513 of the Federal Register, Tuesday, March 17, 1953.

F-8 Merscher, John H. "The 1972 Revision of ASTM Standard Method of Test for Static Coefficient of Friction of Polish Coated Floor Surfaces as Measured by the James Machine." Presented at C.S.M.A. Meeting, December 1972.

Describes differences and similarities of ASTM D21 \& Scientific Committee of CSMA's Wax Division. There has been close cooperation since the organization of D21 in 1950. 
Describes the development of D2047-72, particularly the improvement and limitations of the James machine and the limitations of other tests for slip-resistance.

F-9 Messner vs. Webb's City, Inc., Florida, 62 S0. 2D; 66, 67. (See Hal1 vs. Holland, Florida. 47 So 2D;889).

The rule is that the owner of premises is charged with the duty of exercising ordinary care to keep his premises in a reasonably safe condition for the purposes to which they are adapted. He is responsible for injuries to his invitees due to latent or concealed perils, known to him or which in the exercise of reasonable care, should have been known to him and which were by the invitee unknown or by the exercise of due care could not have been known to such invitee, and, of course, in the absence of a warning by the owner as to such dangers.

F-10 MIL-D-0016680C (SHIPS) Military Specification for Deck Covering Magnesia Aggregate Mixture. Has a section 4.5.9 Non-slip properties which is similar to section 4.5 .8 of MIL-D-18873B (see F-11) except that the oil to be used is SAEIOW and the load to be applied uniformly over a 2 by 4 inch specimen is 22 pounds.

F-11 MIL-D-18873B - Military Specification for Deck Covering Magnesia Aggregate Mixture.

"3.10 Nonslip properties. The covering shall show coefficient of friction not less than that shown in table I when tested as specified in 4.5 .8 and after 1,500 revolutions of the wear test machine specified in 4.5 .9 .1 . 
Table I. Nonslip Properties

Contacting surface conditions Dry wet $0 i 1 y$

Coefficient of static friction

$\begin{array}{llll}\text { Leather } & 0.30 & 0.50 & -- \\ \text { Rubber } & 0.60 & 0.60 & 0.50\end{array}$

Coefficient of sliding friction

$\begin{array}{llll}\text { Leather } & 0.30 & 0.40 & -- \\ \text { Rubber } & 0.60 & 0.60 & 0.30\end{array}$

"4.5.8 Nonslip properties. The coefficient of friction of the deck covering against leather and rubber respectively, shall be determined. The leather shall be oak-tanned sole leather which has been sanded smooth with grade 0 garnet paper. The rubber shall be a vulcanized compound with a hardness range of 60 to 80 durometer ' $A$ '. Tests shall be made with the contact surface dry, wet with a solution of 4 percent sodium chloride in water and oiled, using oil conforming to Symbol 3042 of Specification MIL-L-15016. A load of 33 pounds shall be applied uniformly over the 2 by 4 inch specimen. The determination of static and sliding friction may be made by the inclined plane method or by determining the pull on a spring balance required to start the test piece from rest and then to maintain a constant velocity. The factor of friction shall be the average of four readings."

F-12 MIL-D-3134F Military Specification for Deck Covering Materials.

"3.11 Nonslip properties - When tested as specified in 4.7.6, the deck covering shall show factors of friction not less than shown in Table I. 
Contacting Factor of static

Surface

friction condition

Dry Wet 0ily
Factor of sliding friction condition

:Dry Wet 0ily

$0.30 \quad 0.40 \quad--$

$\begin{array}{lll}0.40 & 0.70 & 0.10\end{array}$

Leather

$0.60 \quad 0.50$

Rubber

$0.60 \quad 0.70$

0.30

"4.7.6 Nonslip properties Two specimens 2 by 4 inch prepared as specified in 4.7 .1 shall be used ..." The rest of this is similar to section 4.5 .8 of MIL-D-18873B (See F-11).

"4.7.1, Preparation of Specimens - Specimens of the sizes as specified in the following tests shall be made by preparing the deck covering in accordance with the manufacturer's instructions. The deck covering shall be troweled on $1 / 8$ inch thick clean steel plates to a thickness of approximately $1 / 4$ inch. The specimens shall be allowed to cure for 96 hours at room temperature before conducting tests.

"Type I materials shall be ground smooth with a power sander using No. 60 paper without water, unless the manufacturer specifies another abrasive paper or procedure. All tests shall be conducted under atmospheric conditions at a temperature of $70^{\circ}$ to $75^{\circ}$ Fahrenheit $(F)$, and a relative humidity of $50 \pm 2$ percent. For specimens intended for immersion tests where corrosion of the steel may occur, areas not covered by the deck covering compound, except the 1 inch strip specified in 4.7 .15 may be protected by a suitable anti-corrosion coating."

F-13 Report of Committee D-21 on Wax Polishes and Related Materials, Presented at the Fifty-fourth annual meeting of ASTM, June 18-22, 1951. 
Under subcommittee IV on Performance Tests is the first mention in ASTM of the James Tester. It is referred to as the UL machine and a cooperative test program was in progress to "investigate the usefulness of the Sigler Pendulum Impact machine and UL machine for determining the slip resistance of waxed floors."

F-14 Report of Committee D-21 on Wax Polishes and Related Materials 1961 Proceedings of ASTM.

Announced that subcommittee IV on Performance Tests "is completing a revision of the proposed method of test for static coefficient of friction of waxed surfaces, which was published in 1954 as information on ly."

John Merscher in F-8 states that there is no news of the next three years but it was finally approved as a tentative method in 1964, after 10 years.

F-15 Report of Committee D-21 on Wax Polishes and Related Materials 1966 Proceedings of ASTM

Established policy of submitting all standards of Committee D-21 to the American Standards Association for approval as American Standards.

F-16 Report of the Scientific Committee 50th Annual Meeting CSMA, Dec. $10,11,12: 1963$.

Written by Perry, Lloyd H.

States that a new subcommittee on Slip Testing was established under Herb Green to: (a) establish limitations for present test methods of measuring slip; (b) explore possible new approaches that may be used for measuring this. 
F-17 Report of Waxes and Floor Finishes Division Proceedings of CSMA 39th Annual Meeting. December 8 \& 9, 1952.

Division Chairman D. M. King reported "that there has been formed a group which has met with Mr. Fitzsimmons of the UL to help develop new test methods for slip resistance. This group last met in September and has made considerable progress although there is nothing yet that they are ready to disclose. That is not of course a CSMA-function. Issuance of any results of the work of this group wi11 come from the UL group rather than from this body." In F-8 Merscher reports that as of Dec. 1972 there was still nothing that they were ready to disclose.

In a sub report by Dan Schoenholz the James Machine is discussed with particular reference to the difficulty of getting a standard piece of leather that works properly. To get two or more pieces of leather to behave in a similar fashion may require checking as many as 10 or 20 pieces.

F-18 "Shoe Sole S1ipperiness Standard Status," Aug. 1974 National Safety News.

Essential1y a repeat of $\mathrm{D}-23$.

F-19 Soap \& Chemical Specialties, May 1971.

This journal contains an article "Candy Does Own Polish S1ip Resistance Testing" and an editorial referring to the article, "Seal-an Alternative" that describes and publicizes how "A private label floor polish manufacturer, who declined to renew his UL contract after 25 years, has just announced a program of sip resistance testing and reporting of his own. --- Such a program is a sensible alternative to what seems to us to be the high-handed and uncompromising attitude adopted by UL." 
Editorial mentions UL refusal to accept toxicity test results performed by any other laboratory and their insistance on rating a 11 aspects of the product to obtain the organization's seal.

F-20 "Standard Method of Test for Static Coefficient of Friction of Polish Coated Floor Surfaces as Measured by the James Machine, "ASTM D2047-72, soon to be revised to ASTM D2047-75.

This specification defines the design and use of the James Machine. The 1975 version will include the following additions:

"2. Applicable Documents

2.2 Other Standard

Proposed Trade Practice Rules for the Floor Wax and Floor Polish Industry, issued March 17, 1953, by the Federa 1 Trade Commission.

"3. Significance

3.1 Floor polishes having a coefficient of static friction, as measured by this method, of not less than 0.5 traditionally have been recognized as providing nonhazardous walkway surfaces. This value of not less than 0.5 meets the requirements for compliance to Rule 5 on the use of terms slip retardant, slip resistant or terms of similar import of the Proposed Trade Practice Rules for the Floor Wax and Floor Polish Industry as issued by the Federal Trade Commission on March 17, 1953."

F-21 Underwriter's Laboratory Re-examination Service - Floor Coating and Finishing Materials, North Brook, I11. 60062.

F-22 "Waxed Floors Are Safe," a Panel Presentation presented before the Waxes, Polishes and Floor Finishes Division, Chemical Specialties Manufacturer's Association Inc., 47th Mid-year meeting, Drake Hotel Chicago, I11., May 15, 16, 17, 1961. 
This has become the "bible" of lawyers on floor slip cases.

1. "Legal Principles of Liability Resulting From Slippage on Waxed Floors," Conner, John D., "The Standard of care is measured by the 'status' of the person who happens to be on the premises." Highest = invitee, next = 1icensee, lowest $=$ trespasser. To be protected against possible litigation one must consider the highest.

Owner can wax and polish floors but must exercise "reasonable care"; that typical of a "reasonably prudent man." Must watch for: wax or polish build up, use of wrong material, floor not being completely dry, improper use of wax and soap, etc.

2. "The Technical Aspects of Alleged Negligence from the Use of Floor Wax," Steinle, J. Vernon.

Part I, a general discussion wherein it is claimed that "in general, it can be stated that the coefficient of friction of waxed floors as compared to the same floor covering unwaxed shows only small differences. It is particularly noteworthy that in a very large number of cases the coefficient of friction for the unwaxed surface is lower than for the same surface waxed, that is, the unwaxed surface is slipperier."

Quotes ASTM D-21 from their published conclusions on the Significance of Coefficient of Friction Measurements in Evaluating the Slip Resistance of Floor Waxes. "It is now generally accepted by those engaged in this study that machine measurements of the coefficient of friction can not correlate in all cases with foot tests on the floor or with safety in use. 
"There are presently no standards of floor safety that can be expressed in terms of accident frequency, coefficient of friction or subjective foot tests in the field."

The UL labs of Chicago for many years used as their criteria for inclusion on their list of "antislip materials" the requirement that the $\mu$ for the waxed surface be greater than $\mu$ for the unwaxed surface. More recently their listing included any material for which $\mu$ was greater than 0.5 when the material was applied to an asphalt tile. "Most commercial waxes are included on the UL 1ist."

The Principal Factors involved in slipping and falling:

A The floor surface

1. $\mu$, floor vs. the sole of the shoe

2. Presence of foreign substances on the floor; water, trash, etc.

3. Condition or state of repair of the floor; presence of a ramp, damaged or missing section of the floor covering.

B The individual's shoe

1. $\mu$ - the sole of the shoevs. the floor.

2. Presence of foreign substance on sole or heel of shoe.

3. Condition or state of repair of the shoe; spike heels, run-down heels, etc.

C Physical features of the individual

1. Method of walking.

2. Distribution of forces.

3. Physical condition; lameness, etc.

D Mental condition of the individual

1. Sanity.

2. Psychology (most important, author) e.g. gloss = slipperiness in the minds of many.

3. Proneness to accidents. 
Check list for floor maintenance

1. Follow directions of manufacturer of any product used.*

2. Keep traffic off a freshly waxed floor till it is dry and/or polished.

3. Wax the entire floor; for psychological reasons.

4. Use the right kind of wax for the floor involved.

5. Do not wax ramps or stairs; again psychological.

6. Do not use heavily oiled mops on waxed floors.

7. Do not wax outside surfaces which are exposed to rain.

Also

1. Keep floors clean and dry and free of a 11 foreign matter.

2. Post warnings of any existing danger.

3. Keep floors well lighted.

4. Inspect and maintain a 11 floor areas regularly.

Check list for floor safety

1. Walk -- don't run.

2. Face in the direction you are walking.

3. Be extra cautious on waxed filoors.

4. Don't read while walking.

5. Keep to the right of center in corridors.

6. Keep far to the right in turning corners, especially blind corners.

7. Enter corridors from offices, stairways and elevators with caution.

8. Don't crowd or push.

9. Avoid horseplay.

10. Wear a practical type work shoe.

Part II of paper

A checkl ist for expert witnesses

Part III of paper

1. The attitude of the manufacturer to alleged negligence due to waxing floors.

2. Pointers for the expert witness.

F-23 "Write to Cancel U.L. Contracts," an editorial in Soap and Chemical Specialties, Dec. 1970. 
Describes the "new" U.L. contract as "calls for 'classification' of a product unless all of its safety aspects, including slip-resistance, are checked by U.L. If a product is merely 'classified' as to slip-resistance, it cannot be 'listed' and bear the U.L. seal. The new contract for a listing also involves agreeing to unannounced factory inspections, delisting without a hearing, and a greatly increased contract fee."

Then suggests that manufacturers must take positive steps to drop their contacts or they will legally remain in force, that many of the large manufacturers are dropping and suggest that there is no reason not to drop.

F-24 Zdanowski, R. E., Report of the Scientific Committee, - Waxes, Polishes and Floor Finishes Division - Proceedings of CSMA 56th mid-year meeting, May 17-20, 1970.

Report of subcommittee $N$, by Chairman Arthur Blake, adoption by unanimous vote "that CSMA adopt as the tentative Standard CSMA Test Method, ASTM D-2047-69(...) with the further provision that any floor polish when tested by this method and has a static coefficient of friction equal to or greater than 0.5, may be considered to meet the requirements of Rule 5 (improper use of the terms 'slip resistant,' 'slip-retardant,' 'anti-slip,' etc.) of the proposed Trade Practice Rules for the Floor Wax and Floor Polish Industry as published by the Federal Trade Commission on March 17, 1953." Cognizance was made of the fact that the precision of the method is \pm 0.05 . The method has subsequently been approved by the Scientific Committee, The Executive Board of the Waxes, Polishes and Floor Finishes Division and finally by the Board of Governors. It is now ready to be bulletinized as a tentative standard CSMA procedure. 


\section{BASIC PRINCIPLES OF FRICTION}

G-1 Amontons, M. "De La Resistance Causée dans Les Machines" Histoire de L'Academie Royale des Sciences, p. 206 (1699).

Early éffort to measure friction by measuring $F$ and $N$ directly and then calculating $F / N=\mu$

Or see "Memoires de Mathematique et de Physique" 1699 pp 259-286.

G-2 Bowden, F. P. and Leben, L. "The Nature of Sliding and the Analysis of Friction." Proceedings of the Royal Society of London, Eng. Vol. 169, 1938-1939, pp. 371-391.

A fundamental paper on friction (dynamic) between "clean" metals, similar and dissimilar. Use of a carefully designed tester to eliminate dynamic effects found stickslip occurring; violent for dissimilar metals and more subdued and regular for similar metals. Found signs of localized welding and tearing of the surface so that sliding involves material below the surface and is not just a surface phenomenon, even when lubricated. Temperature measurements showed a wild fluctuation of surface temperature during sliding with a sudden temperature "flash" at the instant of slip. The exact behavior depends upon the relative physical properties of the metals, particularly on the melting point, and there is evidence that three distinct types of sliding may occur, relating to three distinct types of metallic junctions. "The detailed analysis of the frictional force shows that the classical laws of friction can be regarded only as crude approximations. Earlier theories have assumed that sliding is continuous and that only the surface atoms of the solid are involved. It is clear that neither of these assumptions is correct." 
G-3 Bowden, F. P. and Tabor, D., The Friction and Lubriction of Solids, Parts I and II, Oxford at the Clarendon Press, 1964.

This is a monumental treatment on the subject of friction and contains a particularly complete treatment of the history of the subject. Not too surprizingly most of the material is on friction between two metallic surfaces, with particular emphasis on the effects of lubricants. There is material on the friction of wood and of lubricated rubber, but there is very 1 ittle data relating directly to shoe and flooring surfaces. Chapter XXIV, "Some Early Work on S1iding and Rolling Friction," traces the history of the understanding of friction, starting with the Egyptians, as early as 1900 B.C., and extending up to modern times.

G-4 Conant, F. S. and Liska, J. W., "Friction Studies on Rubberlike Materials." Rubber Chem. Techno1. 33,1218 (1960).

Extends the work of Bowden and Tabor (G-3) to rubber and rubberlike materials. A very comprehensive paper including an extensive bibliography, 165 items. Indicates that for the pressure and velocities likely to occur in normal walking the "laws" of Amontons and coulomb are likely to hold reasonably true.

G-5 Coulomb, C. A. "Theory of Simple Machines," Memoire de L'Academie Royale Sciences, Vol. 10, p. 161 (1781).

First well-known systematic compilation of values of $\mu$.

G-6 Ernst, H. and Merchant, M. E. "Surface Friction of Clean Metals - A Basic Factor in the Metal Cutting Process." Proceedings on Friction and Surface Finish, MIT, June, 1940, pp. 76-101. 
G-7 Gomer, Robert and Smith, C. S. Structure and Properties of Solid Surfaces, A conference arranged by the National Research Council, Lake Geneva, Wisconsin, Sept. 1952. The University of Chicago Press, 1953. A series of papers with chapter VI "The Adhesion of Solids" by F. P. Bowden and P. Tabor being of most interest to floor slip-resistance investigators.

"Although these adhesive forces (at junction of asperities) are very strong, the normal adhesion between surfaces that have been pressed together is usually very smal1. This is due mainly to the effect of released elastic stresses or other types of stress concentration which rupture the junctions as the joining load is removed. For this reason frictional measurements may provide more information about the nature of surface adhesion than the direct measurement of adhesion itself.

"In some cases liquid films produce strong adhesive forces between solid surfaces, but these are essentially due to surface tension and viscous forces. On the other hand, contaminant films which separate the surfaces by more than a few angstroms can produce a profound reduction in the adhesion. In the $1 \mathrm{imit}$, if the surface film completely prevents solid-solid interaction, the adhesive strength at the interface is primarily determined by the strength of the contaminant film itself."

G-8 Graf, Otto Handbuch der Werkstoffprüfung, Vol III, 2nd. Ed., Berlin, Chapter XXII (1957).

G-9 Moore, D. F.; "A History of Research On Surface Effects," WearElsevier Sequoia S. A., Lausanne, 13(1969) 381-412.

"A historical survey of surface texture effects ranging from pipe flow roughness factors to molecular roughness concepts is presented. 
-- Techniques for measuring surface features are classified according to whether the scale of roughness lies in the macro-or micro roughness ranges, and the methods are tabulated. ---It is suggested that at least five parameters are required to uniquely and completely specify surface features in the general case. The effects of texture design on adhesion, hysteresis, lubrication and squeeze films are given, and the subject of macro-elastohydrodynamics has received special emphasis,---." This paper has an extensive bibliography, 83 items.

Moore indicates that the interaction between two surfaces, for example friction, is intimately related to the surface texture of the two surfaces and to how they are affected by any intervening foreign material, such as a lubricant. Most of the work to date has been confined to pairs of rigid surfaces, such as metals, but resilient surfaces, such as leather, rubber, linoleum etc. are also of interest, where the surface is likely to deform under the normal pressures present. He goes on to discuss some of the techniques that have been used to evaluate the surface character of a variety of materials, demonstrating that there is much yet to be learned of surface features and that the learning will require considerable experimental effort.

G-10 Rabinowicz, Ernest; "Stick and Slip," Scientific American, May 1956, Vol 194, No. 5 .

A popularly written article that outlines the historical development of our knowledge of friction and how our improved knowledge has resulted in an understanding of stick slip. "The two types of force that are met most frequently in mechanics are gravity and friction. The former has been studied by great men of science in every age. The latter has been largely neglected, it being assumed that the sliding process holds little intrinsic interest and that 
three simple laws, all discovered before 1800, adequately describe the force of friction. ---The three laws describing the force of friction say that when one solid body slides over another the frictional force (1) is proportional to the load, or pressure of one against the other, (2) is independent of the area of contact, and (3) is independent of the sliding velocity. The first two laws were stated by Leonardo da Vinci and rediscovered in the 1690's by Guillaume Amontons, a French engineer working under the sponsorship of the French Royal Academy of Sciences. The third law was first expressed in 1785 by Charles Augustin de Coulomb, the French physicist better known for his researches in electrostatics.

"If the three laws are correct, friction depends only on the applied load, and the coefficient of friction (the ratio friction-force-toload) for any given materials should be constant under all conditions. The first two laws generally hold true, with no more than 10 percent deviation. But it has been known for some time that friction is not independent of sliding speed. The coefficient of friction between two bodies may vary as much as 30 to 50 percent according to the speed of motion. In 1835 0. Morin of France proposed that, since the frictional force resisting the start of sliding for two bodies at rest was obviously greater than the resistance after they were in motion, there should be two coefficients of friction: a static one, for surfaces at rest, and a kinetic one, for surfaces in motion. Today, as a result of work by a number of investigators, we know that both the static and the kinetic coefficients themselves vary. The kinetic coefficient drops off as the sliding speed increases. And the static coefficient depends to some extent on the length of time the surfaces have been in contact. ---Thus the only satisfactory way to represent the friction coefficient for any pair of surfaces is by two plots, one of the static coefficient as a function of time of contact, the other of the kinetic coefficient as a function of sliding velocity. 
"---In any adhesive process the bond becomes stronger the longer it is left undisturbed. This is why the static coefficient of friction increases with time of contact. In the case of sliding surfaces, the period of contact between points on the two surfaces is, of course, longer when the surfaces slide slowly than when they move rapidly. Consequently, if the slide of one surface over another slows down, friction increases. This is the situation that favors stick slip. However, laboratory tests have developed the unexpected finding that at extremely slow speeds the situation is reversed: as friction increases the sliding velocity also increases." He ascribes this to creep. "These considerations present us with the paradoxical conclusion that there is really no such thing as a static coefficient of friction for most materials. Any frictional force applied to them will produce some creep, i.e. motion." The author presents four graphs of friction versus velocity that depict the evaluation of the friction concept from the late 18th century up to the present. These graphs are duplicated in the body of the paper.

G-11 Swinde11s, A., "Simple Instrument for Measuring Friction," Journal of Scientific Instruments, Vol. 28, No. 7, July 1951.

An ingenious little device for measuring dynamic coefficient of friction between a plate and the rounded tip of a rod. Not suitable for slip-resistance of floors. The plate must be inclined at some angle with respect to the horizontal and then pulled along one of its horizontal edges.

G-12 Tomlinson, G. A., "Moleculer Theory of Friction," Philosophical Magazine, Vo1. 7, series 7, pp. 905-939. 


\section{BIBL IOGRAPHY}

C-1 Abrahamson, E., "Zur Kenntnis der Mechanik des Mittelfusses," Skandinav. Arch. F. Hpysica1. 51: 175-234, 1927.

B-1 Amar, J. "Trottoir dynamographique," Compt. rend., Acad. d. Sc. 163: $130-132,1916$.

G-1 Amontons, M. "De La Resistance Causée dans Les Machines," Histoire de L'Academie Royale des Sciences, p. 206 (1699).

A-1 Barrett, G. F. C. "Observations on the Coefficient of Friction of Shoe Söling Materials," Rubber Journal, Dec. 1, 1956.

C-2 Basler, A., "Kinematographische Aufnahmen mit gleichzeitiger Registrierung von Kraeften," Arbeitsphysical. 8: 585-590, 1935.

C-3 Basler, A. (1936) - Abderhalden. "Handbuch der biologischen Arbeitsmethoden." Abt. V. Organfunktionen. pp. 559-74. (Urban and Schwarzenberg: Berlin).

C-4 Beely, F., "Zur Mechanik des Stehens," Arch. f. Kiin. Chir. 27: 457-471, 1882 .

D-1 "Bell System Practices, Measurement of S1ip-Resistance of Resilient Floors." Principles and Evaluation, Section H51.119 (Aug. 1958) AT\&T Company Staridard.

C-5 Bernstein, N. A. and others, Biodynamics of Locomotion, Vo 1. 1, Moscow, 1935.

D-2 Boone, T.H. \& Auld, C.W. "Standard Measurements of Slipperiness on Walking and Roadway Surfaces," Progress Report 1, NBS Report 7510 , 21 May 1962.

G-2 Bowden, F.P. and Leben, L. "The Nature of STiding and the Analysis of Friction." Proceedings of the Royal Society of London, Eng., Vol. $169,1938-1939$, pp. 371-391.

G-3 Bowden, F. P. and Tabor, D. The Friction and Lubrication of Solids, Parts I and II, Oxford at the Clarendon Press, 1964.

D-3 Braun, R. and Roemer, D. "Influence of Waxes on the Static and Dynamic Friction," Soap/Cosmetics/Chemical Specialties, Dec. 1974.

C-6 Bresler, B. and Franke1, J. P. "The Forces and Moments in the Leg During Level Walking," Transactions of the ASME Vol. 72, No. 1, January 1950.

* These alpha numeric designations locate the references in the preceding annotate bibliography. 
C-7 Bresler, B. and Berry, F. R., "Energy Characteristics of Normal and Prosthetic Ankle Joints," Prosthetic Devices Research Project, Institute of Engineering Research, University of California, Berkeley, Advisory Committee on Artificial Limbs, National Research Council, April 1950.

C-8 Bresler, B. and Berry, F. R., "Energy and Power in the Leg During Normal Level Walking," Prosthetic Devices Research Project, Institute of Engineering Research, University of California, Berkeley, Advisory Committee on Artificial Limbs, National Research Council, May 1951.

D-4 Bunten, J. "Friction Measurements on Soles and Heels, With Particular References to Women's Top-Piece Materials," SATRA, Shoe and Allied Trades Research Association, SATRA House, Kettering, Northants SATRA Memorandum, T. M. 1355.

D-9 Carlet, M. G., "Essai Experimental sur la Locomotion humain, Etude de la Marche." Ann. d. Scien. mat. Zoo1. 16:1-92, 1872.

C-10 Carlsö, Sven, "How Man Moves, Kinesiological Methods and Studies," Heinemann:London, 1972.

C-11 Carlsöö, Sven, "A Method for Studying Walking on Different Surfaces."

E-1 "Causes and Measurement of Walkway S1 ipperiness, "Federal Construction Council Technical Report \#43, National Academy of Sciences National Research Council Publication 899, Washington, D.C. 20418.

E-2 Chaffin, Don B. Private correspondence from visiting professor, Department of Industrial and Systems Engineering, College of Engineering, University of Florida, Gainesville, Fla. 32611.

F-1 Chemical Specialties Manufacturers Association, "CSMA Procedure for Products Classified as to Slip Resistance," CSMA Bulletin \#308-70, December 8, 1928.

D-5 "Coefficient of Friction (S1 ip) Measurements," G-63-10 Fixture, Instron Corp., Canton, Mass.

B-2 "Complex Analysis Produces 'Signature' of Human Step", Product Engineering, July 1, 1968.

G-4 Conant, F. S. and Liska, J. W., "Friction Studies on Rubberlike Materials." Rubber Chem. Technol. 33, 1218 (1960).

G-5 Coulomb, C. A. "Theory of Simple Machines," Memoire de L'Academie Royale Sciences, Vol. 10, p. 161 (1781).

E-3 Cramp, A. P. and Masters, L. W.; "Preliminary Study of the Slipperiness of Flooring"; National Bureau of Standards Report, NBSIR 74-613. 
F-2 CSMA Bulletin No. 245-70, July 22, 1970, Waxes, Polishes and Floor Finishes Division.

F-3 CSMA Bulletin No. 308-70, December 8, 1970. CSMA Procedure for Products Classified as to Slip Resistant, signed by John D. Conner, General Counsel \& W. S. Jessop, Chairman Standards and Specifications Appraisal Committee.

F-4 CSMA Tentative Method, "Comparative Determination of S1ip Resistance of Floor Polishes," CSMA Bulletin No. 245-70, July 22, 1970.

B-3 Cunningham, D. M., "Components of Floor Reactions During Walking," Prosthetic Devices Research Project, Institute of Engineering Research, University of California, Berkeley. Advisory Committee on Artificial Limbs, National Research Council. Series II, Issue 14, November 1950.

B-4 Cunningham, Don M. and Brown, Wayne G., "Two Devices for Measuring the Forces Acting on the Human Body During Walking," University of California, Berkeley, Proceedings of the Society for Experimental Stress Analysis, Vol. 9, No. 2, 1952.

D-6 Day, S. S. - Bowen, H. D. \& Hader, R. J. "Skid Resistance of Floor Surfaces and Finishes," Resilient Floor Coverings, Hard Floor Surfaces and Wood Floor Finishes, Tech. Bul. No. 200, North Carolina Agricultural Experiment Station In Cooperation with the School of Home Economics. The University of North Carolina at Greensboro, Dec. 1970.

D-7 Day, S. S. and Hodges, M. B. "Factors Affecting Skid Resistance of Hard Floor Surfaces," Hospitals, J.A.H.A. April 16, 1967, Vol. 41.

D-8 Day, S. S. \& Shamburger, E. "Factors Controlling Skid Resistance of Resilient Floor Coverings," Hospitals, J.A.H.A., April 16, 1965, Vo1. 39.

D-9 Day, S. S.; Tuten, F.; Trogdon, J.; and Bowen, H. "Measurement of the Skid Resistance of Resilient Smooth Floor Surfaces." Journal of Home Economics, Vol. 56, No. 10, Dec. 1974.

F-5 Doering, R. D., "Defining a Safe Walking Surface," National Safety News, August 1974.

A-2 Ekkebus, C. F. and Killey, W., "Measurement of Safe Walkway Surfaces," Soap/Cosmetics/Chemical Specialties for Feb. 1973.

B-5 "Electronic Step-Meter Reveals Mechanics of Walking." National Bureau of Standards Technical News Bulletin, 1951, 35(4), 50.

B-6 Elftman, Herbert, "The Measurement of the External Force in Walking," Science 88:152-153, 1938. 
C-12 Elftman, Herbert, "A Cinematic Study of the Distribution of Pressure in the Human Foot," Anat. Rec. 59:481-490, 1934.

C-13 Elftman, H. (1939) - Amer. J. Physiol. 125:339-56.

G-6 Ernst, H. and Merchant, M. E. "Surface Friction of Clean Metals - A Basic Factor in the Metal Cutting Process." Proceedings on Friction and Surface Finish, MIT, June 1940, pp. 76-101.

D-10 Esmay, M. L. and Segerlind, L. J., "Analysis of Frictional Characteristics of Stairway Tread Covering Materials," Transactions of the American Society of Agricultural Engineers, Vol. 7, No. 2, 1964.

D-11 "Evaluating the S1ip Resistance of Floor Waxes, The Significance of Friction Measurements," ASTM Bulletin, Sept. 1958.

D-12 Ewerdah1, S. "Ha 1ksäkerhet Hos Golvbeläggningsmaterial; Byggmästaren, 1938, 17, 447-451, N:r 39 1938. Inneha 17; Investigations of Various Floor Materials in Relation to Slipperiness.

F-6 Fed. Spec. RR-G-1602, Ju7y 10, 1970, Federal Specification Grating, Meta1, Other Than Bar Type (Floor, Except for Naval Vessels).

F-7 Federal Trade Commission, Washington; "Proposed Trade Practice Rules for the Floor Wax and Floor Polish Industry"; For release in morning newspapers of Tuesday, March 17, 1953.

C-14 Fischer, 0., "Der Gang des Menschen, I. Thiel: Versuche am unbelasteten und belasteten Menschen, Abhandlungen der Mathematisch - Physischen Classe der Königlich Sächsischen." Gesellschaft der Wissenschaften. Classe 21, p. 153-322, Leipzig, 1895.

C-15 Fisher, 0., "Der Gang des Menchen, II. Thiel: Die Bewegung des Gasammtschwer punktes und die äusseren Kräte, Abhandlungen der Mathematisch Physischen Classe der Königlich Sächsischen." Gesellschaft der Wissenschaften. Classe 25, p. 3-130, Leipzig, 1895.

D-13 Frederick, W. S., "Description of a New Portable Slip Testing Machine," 44th Mid-year Meeting Proceedings of the Chemical Specialties Manufacturer Association Inc., N.Y. , May 1958.

B-7 "Fundamental Studies of Human Locomotion and Other Information Relating to the Design of Artificial Limbs." University of California, report to U.S. National Research Council, 1947.

C-16 Fung, Y.C. \& Anliker, M. "Biomechanics, Its foundations and Objectives," edited by Y. C. Fung and M. Anliker. Published by Prentice-Hall, Inc., Englewood Cliffs, New Jersey, 1972. 
D-14 Gavan, F. M., Discussion of C. H.. Irvine Paper, "A New S7ipmeter for Evaluating Walkway Slipperiness, "Materials Research \& Standards, Vol. 7, No. 12, December, 1967.

D-15 Gavan, F. M. \& Vanaman, J. B., "Significant Variables Affecting Results Obtained with the James Friction Machine,"iMaterials Research \& Standards, Vol. 8, No. 11, November, 1968.

D-16 Giles, C. G.; Sabey, B. E.; and Cardew, K. H. F. "Development and Performance of the Portable Skid Resistance Tester." Rubber Chem. Technol. 38,840 (1965).

G-7 Gomer, Robert and Smith, C. S. Structure and Properties of Solid Surfaces, A Conferençe arranged by the National Research Council, Lake Geneva, Wisconsin, Sept. 1952. The University of Chicago Press, 1953. A series of papers with chapter VI "The Adhesion of Solids," by F. P. Bowden and P. Tabor being of most interest to floor slip-resistance investigators.

D-17 Gough, V. E., "Simple Direct-Reading Friction Meter," Journal of Scientific Instruments, Vo1. 30, No. 10, October, 1953.

G-8 Graf, Otto, Handbuch der Werkstoffprüfung, Vol. III, 2nd Ed., Berlin, Chapter XXII (1957).

D-18 Gurney, S. W., "Is the Floor too Slippery?" National Safety News, 1940, Aug. 22.

E-4 Gutt, W. Private correspondence from Department of the Environment, Building Research Establishment, Building Research Station, Garston, Watford, WD2 7JR.

B-8 Harper, F. C.; Warlow, W. J.; and Clarke, B. L. "The Forces Applied to the Floor by the Foot in Walking, "National Building Studies Research Paper \#32, Department of Scientific and Industrial Research Building Research Station, London 1961.

D-19 Hartley, Owen, "How to Use a Floor S7 ip Tester", The Executive Housekeeper Vol. 15, No. 11, Dec. 1968.

E-5 Heath, Arthur L. Private correspondence with Associate Director, Myodynamics Laboratory, The University of Rochester, School of Medicine and Dentistry and Strong Memorial Hospital, 260 Crittenden Boulevard, Rochester, N.Y. 14620.

C-17 Holden, T. S. and Muncey, R. W., "Pressures on the Human Foot During Walking," Aust. J. App. Sci., 1953, 4(3) 405. 
E-6 Hopkins, S. K. "Elusive Factor in Falls: The Shoe Sole," National Safety News, NSANA, Nov. 1966, pp. 34-39.

D-20 Hunter, R. B., "A Method of Measuring Frictional Coefficients of Walkway Materials," Journal of Research, NBS, Vol. 5, p. 329 (Aug. 1930), RP204.

D-21 "Instructions for Using the Portable Skid-Resistance Tester," Road Research, Road Note No. 27, Department of Scientific and Industrial Research, Road Research Laboratory, London: Her Majesty's Stationery Office: 1960.

D-22 Irvine, C. H. "A New Slipmeter for Evaluating Walkway Slipperiness," Materials Research and Standards, MTRSA, Vol. 7, No. 12, Dec. 1967 pp. 535-541.

D-23 Irvine, Charles H., "Shoe Sole Slipperiness on Structural Steel," ASTM Materials Research and Standards, Vol. 10, No. 4, April 1970.

E-7 Jablonsky, R. D. Private correspondence from Truesdail Laboratories, Inc., Chemists, Microbiologists, Engineers, 4101 N. Figueroa Street, Los Angeles, Cal. 90065.

D-24 James, Sydney V., "What is a Safe Floor Finish?" Soap and Sanitary Chemicals, Oct. 1944.

D-25 Johnson, Bayard S., "A Discussion of Some Factors Influencing Slip Resistance Measurements," CSMA, Proceedings of the 44th Midyear Conference, May 1958.

E-8 "Keeping Employees on their Feet," National Safety News, Sept. 1970.

D-26 Keilett, P. H. "Modern Solings in Wear," SATRA Information Publication I. P. 16, SATRA Symposium on Injection Moulding, June 28, 1968.

C-18 Klopsteg, P. E., Wilson, P. D., et a1. Human Limbs and Their Substitutes. New York, 1954, McGraw Hi11.

C-19 Marey, E. J., "De 1a Locomotion terrestre chez les bipedes et les quadrupedes," J. de L'Anat, et de la Physiol. 9:42-80, 1873.

D-27 "Measurement of the S1ipperiness of Walkway Surfaces," Rubber Age, Vol. 62, Dec. 1947, pp. 296-297. No author, but it appears to have been written by Percy Sigler.

F-8 Merscher, John H. "The 1972 Revision of ASTM Standard Method of Test for Static Coefficient of Friction of Polish Coated Floor Surfaces as Measured by the James Machine." Presented at C.S.M.A. Meeting December 1972. 
F-9 Messner vs. Webb's City, Inc., Florida, 62 S0. 2D; 66, 67. (See Hall vs. Holland, Florida. 47 SO 2D;889.)

F-10 MIL-D-0016680C (SHIPS) Military Specification for Deck Covering Magnesia Aggregate Mixture.

F-11 MIL-D18873B - Military Specification for Deck Covering Magnesia Aggregate Mixture.

F-12 MIL-D-3134F Military Specification for Deck Covering Materials.

D-28 "Model 80 Floor Friction Tester" Promotional Literature, Technical Products Co., 264 Park Ave., N. Caldwe11, N.J. 07006.

D-29 Modern Sanitation and Building Maintenance, Vol. 11, No. 7, p. 6 (1959).

G-9 Moore, D. F., "A History of Research On Surface Effects," Wear-Elsevier Sequoia S. A., Lausanne, 13 (1969) 381-412.

D-30 "Progress Report to the National Safety Council Committee on Safe Walkway Surfaces," 0ct. 1, 1949 - Mar. 31, 1950.

D-31 "Proposed Method of Test for Measuring the Static Coefficient of Friction of Waxed Floor Surfaces," and "Proposed Method of Test for Measuring the Dynamic Coefficient of Friction of Waxed Floor Surfaces," ASTM Bulletin, No. 196, Feb. 1954.

G-10 Rabinowicz, Ernest, "Stick and STip," Scientific American, May 1956, Vol. 194 , No. 5.

C-20 Rehman, I. (1947) - Arch. Phys. Med. 28:749-56.

F-13 Report of Committee D-21 on Wax Polishes and Related Materials, Presented at the Fifty-fourth annual meeting of ASTM, June 18-22, 1951.

F-14 Report of Committee D-21 on Wax Polishes and Related Materials - 1961 Proceedings of ASTM.

F-15 Report of Committee D-21 on Wax Polishes and Related Materials - 1966 Proceedings of ASTM.

F-16 Report of the Scientific Committee 50th Annual Meeting CSMA, Dec. 9, 10, 11, 12: 1963.

F-17 Report of Waxes and Floor Finishes Division Proceedings of CSMA 39th Annual Meeting. December 8 \& 9, 1952.

D-32 Robinson, W. H. and Kopf, R. E. "Evaluation of the Horizontal Pull Slipmeter," Materials Research and Standards, Vol. 9, No. 7, American Society for Testing and Materials, July 1969. 
E-9 Rodstein, Manuel, MD, "Accidents Among the Aged," 1963, National Safety Counci1, 425 N. Michigan Avenue, Chicago, I11. $606114 p p$.

D-33 Schjödt, R. "Measurements of Human Reaction to Hardness of Floor Covering," ASTM Bulletin No. 247, July 1960.

A-3 Schuster, K. "Slip - An Investigation of Practical Accident Prevention," Die Berufsgenossenschaft/Betriebssicherheit/September 1966.

C-21 Schwartz, R. P.; Heath, A. L.; and Wright, J. N. "Electrobasographic Method of Recording Gait," Archives of Surgery, Nov. 1933, Vol. 27.

C-22 Schwartz, R. P.; Heath, A. L.; Miziek, W.; and Wright, J. N., "Kinetics of Human Gait," The Journal of Bone and Joint Surgery, Vol. XVI, No. 2, Apr. 1934.

C-23 Schwartz, R. P. and Heath, A. L. "The Definition of Human Locomotion on the Basis of Measurement," (1947), The Journal of Bone and Joint Surgery, 29: No. 1, 203-14., Jan. 1947.

C-24 Schwartz, R. P.; Heath, A. L.; Morgan, D. W.; and Towns, R. C.; "A Quantitative Analysis of Recorded Variables in the Walking Pattern of 'Normal' Adults"; the journal of Bone and Joint Surgery, Vol. 46A, No. 2, pp. 324-334, March 1964.

F-18 "Shoe Sole Slipperiness Standard Status," Aug. 1974, National Safety News.

D-35 Sigler, P. A. "Relative Slipperiness of Floor and Deck Surfaces." U.S. National Bureau of Standards, Building Materials and Structures Report, B.M.S. 100.

D-35 Sigler, P. A., Geib, M. N., Boone, T. H. "Measurement of the Slipperiness of Walkway Surfaces." J. Res. National Bureau of Standards, 1948, 40, 339. Also Research Paper RP 1879, May 1948.

F-19 Soap \& Chemical Specialties, May 1971.

D-36 "Standard Method of Test for Measuring Surface Frictional Properties Using the British Portable Tester," ASTM Designation E303-69.

F-20 "Standard Method of Test for Static Coefficient of Friction of Polish Coated Floor Surfaces as Measured by the lames Machine," ASTM n2047-72, scon to be revised to ASTM D2047-75. 
C-25 Steindler, A., "Mechanics of Normal and Pathological Locomotion in Man," by Arthur Steindler, M.D. F.A.C.S., Professor of Orthopedic Surgery, State University of Iowa, Iowa City, Iowa. Published by Charles C. Thomas, Springfield, Illinois, and Baltimore, Maryland, 1935.

C-26 Steindler, A. "Kinesiology, of the Human Body, Under Normal and Pathological Conditions," by Arthur Steindler, M.D. (Hon.) F.R.C.S., Eng. F.A.C.S, F.I.C.S., Professor Orthopedic Surgery, Emeritus, State University of Iowa, Head of Orthopedic Department, Mercy Hospital, Iowa City, Iowa. Publ ished by Charles C. Thomas, Springfield, I11., 1955.

C-27 Strasser, H., Lehrbuch der Muskel und Gelenk Mechanik, 4 vols., Berlin, 1908-17.

C-28 Sussman, A. and Goode, R., "The Magic of Walking."

G-11 Swindells, A., "Simple Instrument for Measuring Friction," Journal of Scientific Instruments, Vol. 28, No. 7, July 1951.

D-37 "Tentative Test Method for Qualitative Determination of Slip Resistance of Floor Polishes," CSMA Committee "N" CSMA Bulletin No. 117-68, May $7,1968$.

G-12 Tomlinson, G. A., "Moleculer Theory of Friction," Philosophical Magazine, Vol. 7, series 7, pp. 905-939,

F-21 Underwriter's Laboratory Re-examination Service - Floor Coating and Finishing Materials, North Brook, I11. 60062.

E-10 Waters, E. H., "Some Special Problems of Floor Design From the Safety Aspect," Report No. L10, Division of Building Research, Commonwealth Scientific and Industrial Research Organization, Commonwealth of Australia, Melbourne, 1960.

F-22 "Waxed Floors Are Safe," A panel presentation presented before the Waxes, Polishes and Floor Finishes Division, Chemical Specialties Manufacturer's Association Inc., 47th Mid-year meeting, Drake Hotel, Chicago, I11., May 15, 16, 17, 1961.

D-38 Weirich, C. L., "Static Coefficient of Friction, Significance of Test Results," Clarence L. Weirch, presented before the CSMA, May 1958.

D-39 Williams, W. D., Smith, J. A. and Draugelis, F. J. "TOPAKA, A New Device and Method for Measuring Slip Resistance of Polished Floors," Soap/ Cosmetics/Chemical Specialties, July 1972.

D-40 Wilson, Angus and Mahoney, Patrick, "Measuring Frictional Properties of Soles and Heels," Rubber World, March 1972. 
E-11 Wilson, Angus F. Private correspondence from Chief, Polymer Applications Group; Polymers and Organic Materials Br; Materials Applications Division Clothing; Equipment and Materials Engineering Laboratory. U.S. Army Natick Laboratories, Natick, Mass.

F-23 "Write to Cancel U.L. Contracts," an editorial in Soap and Chemical Specialties, Dec. 1970.

F-24 Zdanowski, R. E., Report of the Scientific Committee - Waxes, Polishes and Floor Finishes Devision - Proceedings of CSMA 56th mid-year meeting, May 17-20, 1970. 


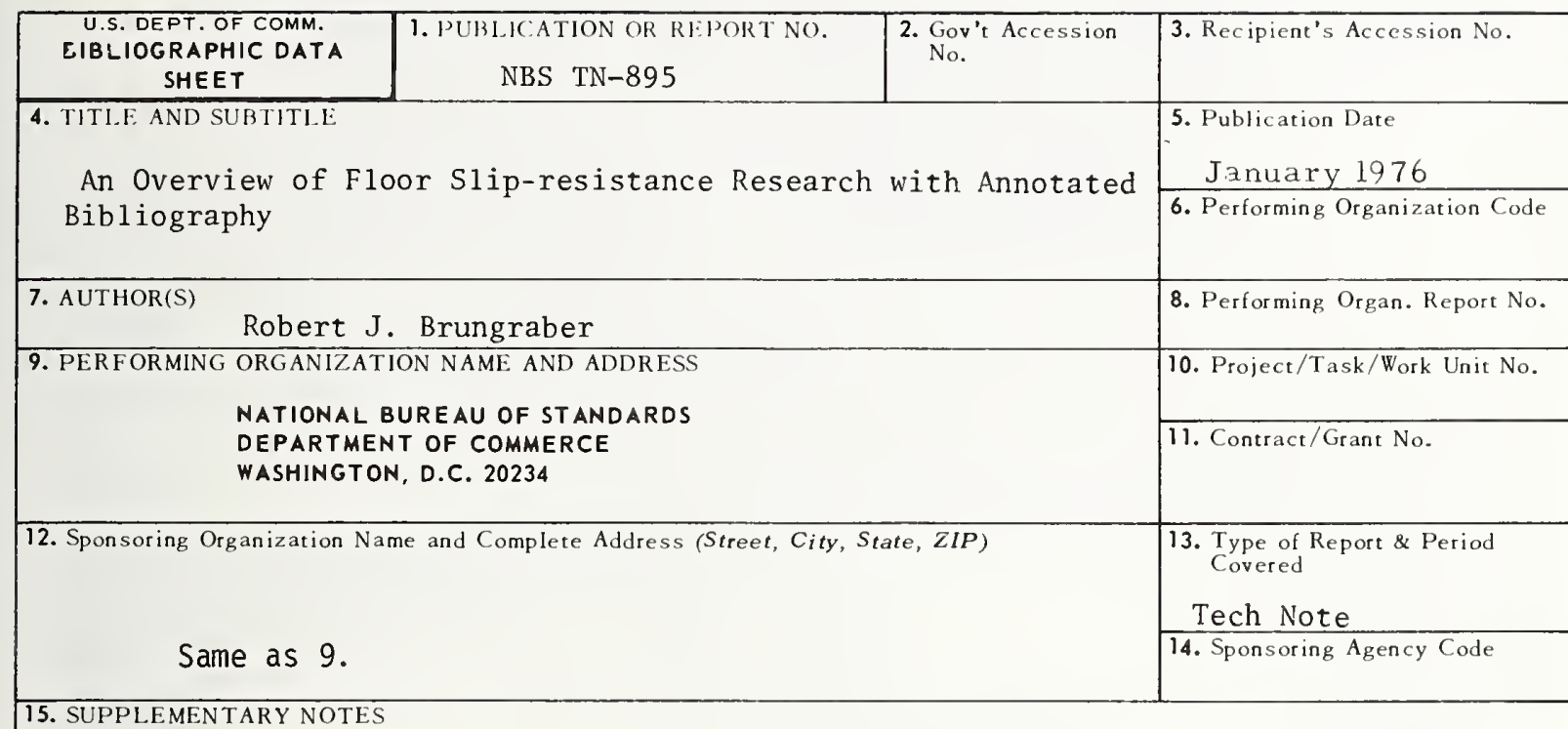

16. ABSTRACT (A 200-word or less factual summary of most significant information. If document includes a significant bibliography or literature survey, mention it here.)

Slips and falls in the home as well as in public buildings have reached serious proportions $(8,000,000$ accidents per year in the home, resulting in 9,600 deaths and 1,600,000 disabling injuries). This paper reviews the literature relating to this problem. Based on studies of kinesiology and anthropometry, the coefficient of friction between foot surfaces and floor surfaces is found to be a significant parameter controlling slips and falls. A review of the general study of friction and a critical appraisal of methods for determining the coefficient of friction on slip-resistance of floors leads to a guide for selection of slip-resistance criteria. The paper concludes with a discussion of the legal aspects of the problem and the present status of slip-resistance specifications.

17. KEY WORDS (six to twelve entries; alphabetical order; capitalize only the first letter of the first key word unless a proper name; separated by semicolons)

Building safety; floor surface friction; occupancy safety; slip-resistance; slip-resistance testers; walking friction.

\begin{tabular}{|c|c|c|}
\hline $\begin{array}{l}\text { 18. AVAILABILITY } \\
\square X \text { Unlimited } \\
\square \text { For Official Distribution. Do Not Release to NTIS }\end{array}$ & $\begin{array}{l}\text { 19. SECURITY CLASS } \\
\text { (THIS REPORT) } \\
\text { UNCL ASSIF IED }\end{array}$ & $\begin{array}{l}\text { 21. NO. OF PAGES } \\
113\end{array}$ \\
\hline $\begin{array}{l}\text { x Order From Sup. of Doc., U.S. Government Printing Office } \\
\text { Washington, D.C. } 20402, \text { SD Cat. No.C13.46:895 }\end{array}$ & $\begin{array}{l}\text { 20. SECURITY CLASS } \\
\text { (THIS PAGE) }\end{array}$ & 22. Price \\
\hline $\begin{array}{l}\square \text { Order From National Technical Information Service (NTIS) } \\
\text { Springficld, Virginia 22151 }\end{array}$ & UNCLASSIFIED & $\$ 2.30$ \\
\hline
\end{tabular}




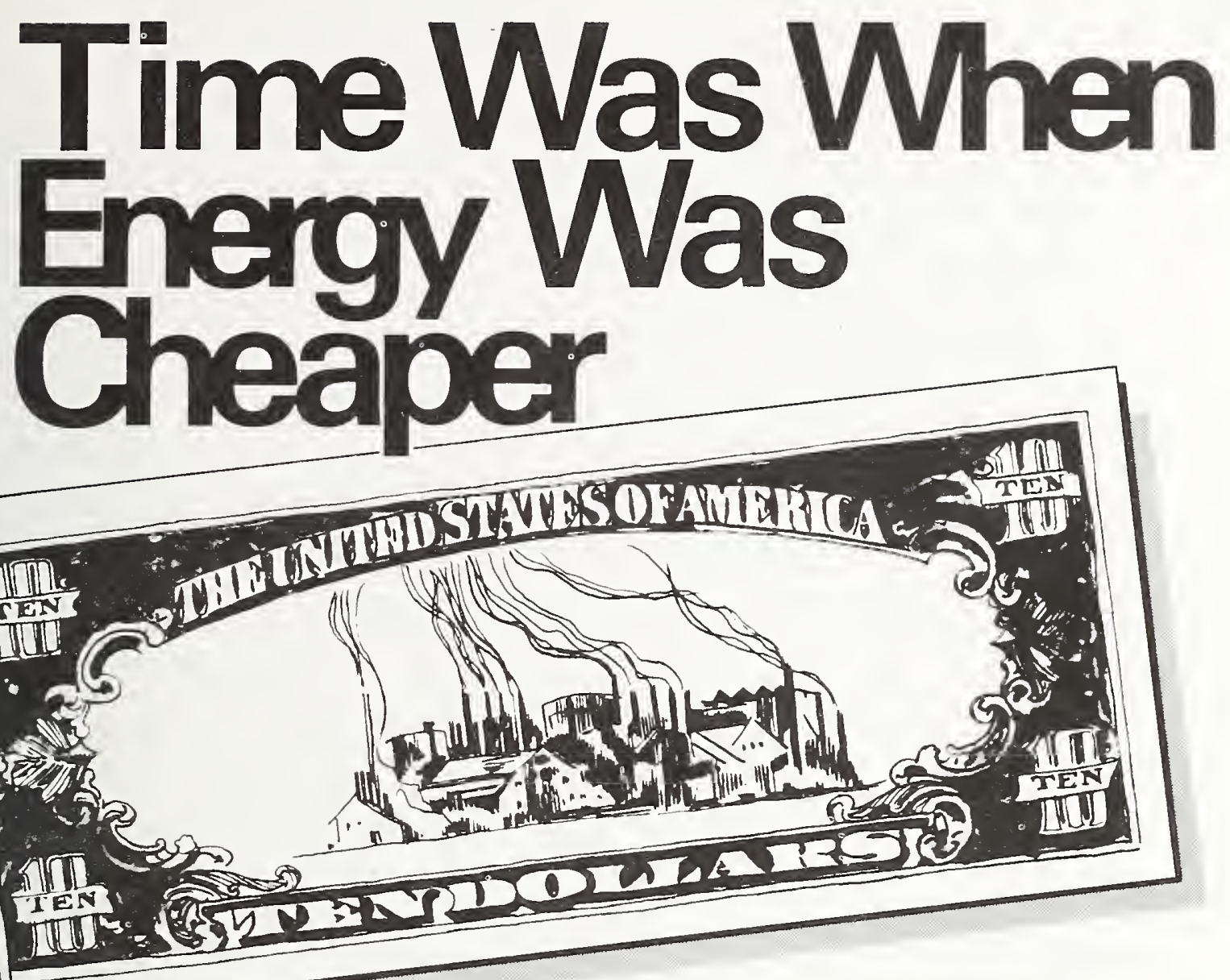

\section{...but thai's all changed now.}

Today, increased energy costs-caused by increasing demand-boost the price of consumer goods, fuel inflation, and hurt our balance of payments.

That's why conserving energy is a must today, especially for you in the business and industry community which uses two thirds of our nation's energy.

Now... there's a book to tell you how to do it. It's called EPIC-the Energy Conservation Program Guide for Industry and Commerce. Prepared for you by the Commerce Department's National Bureau of Standards in cooperation with the Federal Energy Administration.

EPIC is a comprehensive handbook that can help you establish or improve an energy con. servation program in your organization.

Not only industry and commerce but also hospitals, universities, research institutes, ANY organization that uses energy-and has to pay the bills - will want a copy of EPIC.

$E P I C$ outlines in detail the steps in setting up an energy conservation program.

It contains a checklist of more than 200 Energy Conservation Opportunities-suggestions to save energy in a dozen different areas.

EPIC's actual case histories of energy saving actions help you estimate your potential for saving energy-and reducing costs.

And EPIC contains much more-financial analysis procedures to evaluate projects, sources of information on energy conservation, engineering data and factors, an energy conservation bibliography.

Make EPIC part of your plan to control energy use and costs. Make EPIC part of your contribution to using energy resources wisely... so we can keep America working and growing.

To order your copy of EPIC, send \$2.90 per copy (check, moriey order or Superintendent of Documents Coupons) to Super(1) Government Printing Office, Washington, D.C. 20402. Ask for NBS Handbook 115, EPIC, C13.11:115.

Discount of $25 \%$ on orders of 100 copies or more.

U.S. DEPARTMENT OF COMMERCE / National Bureau of Standards FEDERAL NNERGY ADMINISTRATION / Conservation and Environment 



\section{PERIODICALS}

JOURNAL OF RESEARCH reports National Bureau of Standards research and development in physics, mathematics, and chemistry. It is published in two sections, a vailable separately:

\section{- Physics and Chemistry (Section A)}

Papers of interest primarily to scientists working in these fields. This section covers a broad range of physical and chemical research, with major emphasis on standards of physical measurement, fundamental constants, and properties of matter. Issued six times a year. Annual subscription: Domestic, \$17.00; Foreign, $\$ 21.25$.

\section{- Mathematical Sciences (Section B)}

Studies and compilations designed mainly for the mathematician and theoretical physicist. Topics in mathematical statistics, theory of experiment design, numerical analysis; theoretical physics and chemistry, logical design and programming of computers and computer systems. Short numerical tables. Issued quarterly. Annual subscription: Domestic, $\$ 9.00$; Foreign, $\$ 11.25$.

DIMENSIONS/NBS (formerly Technical News Bulletin)-This monthly magazine is published to inform scientists, engineers, businessmen, industry, teachers, students, and consumers of the latest advances in science and technology, with primary emphasis on the work at NBS. The magazine highlights and reviews such issues as energy research, fire protection, building technology, metric conversion, pollution abatement, health and safety, and consumer product performance. In addition, it reports the results of Bureau programs in measurement standards and techniques, properties of matter and materials, engineering standards and services, instrumentation, and automatic data processing.

Annual subscription: Domestic, $\$ 9.45$; Foreign, $\$ 11.85$.

\section{NOMPERIODICALS}

Monographs-Major contributions to the technical literature on various subjects related to the Bureau's scientific and technical activities.

Handbooks-Recommended codes of engineering and industrial practice (including safety codes) developed in cooperation with interested industries, professional organizations, and regulatory bodies.

Special Publications-Include proceedings of conferences sponsored by NBS, NBS annual reports, and other special publications appropriate to this grouping such as wall charts, pocket cards, and bibliographies.

Applied Mathematics Series-Mathematical tables, manuals, and studies of special interest to physicists, engineers, chemists, biologists, mathematicians, computer programmers, and others engaged in scientific and technical work.

National Standard Reference Data Series-Provides quantitative data on the physical and chemical properties of materials, compiled from the world's literature and critically evaluated. Developed under a world-wide program coordinated by NBS. Program under authority of National Standard Data Act (Public Law 90-396).

NOTE: At present the principal publication outlet for these data is the Journal of Physical and Chemical Reference Data (JPCRD) published quarterly for NBS by the American Chemical Society (ACS) and the American Institute of Physics (AIP). Subscriptions, reprints, and supplements available from ACS, 1155 Sixteenth St. N. W., Wash. D. C. 20056.

Building Science Series-Disseminates technical information developed at the Bureau on building materials, components, systems, and whole structures. The series presents research results, test methods, and performance criteria related to the structural and environmental functions and the durability and safety characteristics of building elements and systems.

Technical Notes-Studies or reports which are complete in themselves but restrictive in their treatment of a subject. Analogous to monographs but not so comprehensive in scope or definitive in treatment of the subject area. Often serve as a vehicle for final reports of work performed at NBS under the sponsorship of other government agencies.

Voluntary Product Standards-Developed under procedures published by the Department of Commerce in Part 10, Title 15, of the Code of Federal Regulations. The purpose of the standards is to establish nationally recognized requirements for products, and to provide all concerned interests with a basis for common understanding of the characteristics of the products. NBS administers this program as a supplement to the activities of the private sector standardizing organizations.

Federal Information Processing Standards Publications (FIPS PUBS)-Publications in this series collectively constitute the Federal Information Processing Standards Register. Register serves as the official source of information in the Federal Government regarding standards issued by NBS pursuant to the Federal Property and Administrative Services Act of 1949 as amended, Public Law 89-306 (79 Stat. 1127), and as implemented by Executive Order 11717 ( 38 FR 12315, dated May 11, 1973) and Part 6 of Title 15 CFR (Code of Federal Regulations).

Consumer Information Series-Practical information, based on NBS research and experience, covering areas of interest to the consumer. Easily understandable language and illustrations provide useful background knowledge for shopping in today's technological marketplace.

NBS Interagency Reports (NBSIR) - A special series of interim or final reports on work performed by NBS for outside sponsors (both government and non-government). In general, initial distribution is handled by the sponsor; public distribution is by the National Technical Information Service (Springfield, Va. 22161) in paper copy or microfiche form.

Order NBS publications (except NBSIR's and Bibliographic Subscription Services) from: Superintendent of Documents, Government Printing Office, Washington, D.C. 20402.

\section{BIBLIOGRAPHIC SUBSCRIPTION SERVICES}

The following current-awareness and literature-survey bibliographies are issued periodically by the Bureau: Cryogenic Data Center Current Awareness Service

A literature survey issued biweekly. Annual subscription: Domestic, $\$ 20.00$; foreign, $\$ 25.00$.

Liquefied Natural Gas. A literature survey issued quarterly. Annual subscription: $\$ 20.00$.

Superconducting Devices and Materials. A literature survey issued quarterly. Annual subscription: $\$ 20.00$. Send subscription orders and remittances for the preceding bibliographic services to National Technical Information Service, Springfield, Va. 22161.

Electromagnetic Metrology Current Awareness Service Issued monthly. Annual subscription: \$24.00. Send subscription order and remittance to Electromagnetics Division, National Bureau of Standards, Boulder, Colo. 80302 . 
U.S. DEPARTMENT OF COMMERCE

National Bureau of Standards

Washingtan, D.C. 20234

POSTAGE AND FEES PAID U.S. DEPARTMENT OF COMMERCE $C O M-295$

DFFICIAL BUSINESS

Penalty for Private Use, $\$ 300$
SPECIAL FOURTH.CLASS RATE BOOK 